\title{
Focal Brain Injury Associated with a Model of Severe Hypoxic-Ischemic Encephalopathy in Nonhuman Primates
}

\author{
Ryan M. McAdams ${ }^{\text {a }}$ Ronald J. McPherson ${ }^{a}$ Raj P. Kapur ${ }^{b}$ Sandra E. Juul ${ }^{a}$ \\ ${ }^{a}$ Division of Neonatology, Department of Pediatrics, University of Washington, and ${ }^{\mathrm{b}}$ Department of Pathology, \\ Seattle Children's Hospital, Seattle, WA, USA
}

\section{Keywords}

Perinatal asphyxia $\cdot$ Hypoxic-ischemic encephalopathy Magnetic resonance imaging . Dexmedetomidine

\begin{abstract}
Worldwide, hypoxic-ischemic encephalopathy (HIE) is a major cause of neonatal mortality and morbidity. To better understand the mechanisms contributing to brain injury and improve outcomes in neonates with HIE, better preclinical animal models that mimic the clinical situation following birth asphyxia in term newborns are needed. In an effort to achieve this goal, we modified our nonhuman primate model of HIE induced by in utero umbilical cord occlusion (UCO) to include postnatal hypoxic episodes, in order to simulate apneic events in human neonates with HIE. We describe a cohort of 4 near-term fetal Macaca nemestrina that underwent 18 min of in utero UCO, followed by cesarean section delivery, resuscitation, and subsequent postnatal mechanical ventilation, with exposure to intermittent daily hypoxia (3 min, 8\% $\mathrm{O}_{2} 3-8$ times daily for 3 days). After delivery, all animals demonstrated severe metabolic acidosis $(\mathrm{pH} 7 \pm$ 0.12 ; mean \pm SD) and low APGAR scores ( $<5$ at 10 min of age). Three of 4 animals had both electrographic and clinical seizures. Serial blood samples were collected and plasma me-
\end{abstract}

\section{KARGER}

(C) 2017 S. Karger AG, Basel

E-Mail karger@karger.com

www.karger.com/dne tabolites were determined by 2-dimensional gas chromatography coupled with time-of-flight mass spectrometry (GC $\times$ GC-TOFMS). The 4 UCO animals and a single nonasphyxiated animal (delivered by cesarean section but without exposure to UCO or prolonged sedation) underwent brain magnetic resonance imaging (MRI) on day 8 of life. Thalamic injury was present on MRI in 3 UCO animals, but not in the control animal. Following necropsy on day 8 , brain histopathology revealed neuronal injury/loss and gliosis in portions of the ventrolateral thalamus in all $4 \mathrm{UCO}$, with 2 animals also demonstrating putamen/globus pallidus involvement. In addition, all 4 UCO animals demonstrated brain stem gliosis, with neuronal loss present in the midbrain, pons, and lateral medulla in 3 of 4 animals. Transmission electron microscopy imaging of the brain tissues was performed, which demonstrated ultrastructural white matter abnormalities, characterized by perinuclear vacuolation and axonal dilation, in 3 of 4 animals. Immunolabeling of Nogo-A, a negative regulator of neuronal growth, was not increased in the injured brains compared to 2 control animals. Using GC $\times$ GC-TOFMS, we identified metabolites previously recognized as potential biomarkers of perinatal asphyxia. The basal ganglia-thalamus-brain stem injury produced by UCO is consistent with the deep nuclear/brainstem injury pattern seen in human neonates after severe, abrupt hypoxic-ischemic insults. The

Sandra E. Juul, MD, PhD

Division of Neonatology, Department of Pediatrics, University of Washington 1959 NE Pacific Street, HSB RR542D, UW Box 356320

Seattle, WA 98195-6320 (USA)

E-Mail sjuul@uw.edu 
UCO model permits timely detection of biomarkers associated with specific patterns of neonatal brain injury, and it may ultimately be useful for validating therapeutic strategies to treat neonatal HIE.

(c) 2017 S. Karger AG, Basel

\section{Introduction}

Intrapartum hypoxic events ("birth asphyxia”) are a major cause of neonatal mortality responsible for approximately 1 in 5 of all neonatal deaths worldwide [1]. These intrapartum hypoxic events often result in hypoxic-ischemic encephalopathy (HIE), characterized by decreased consciousness, tone, and reflexes, with clinical symptoms that include seizures, impaired respiration, poor feeding abilities, and apneic episodes [2,3]. Many questions persist regarding the underlying cellular, molecular, and genetic mechanisms that may influence both the susceptibility of fetuses to develop HIE and their responses to treatment with therapeutic hypothermia (TH). To address these questions and promote direct translation of experimental findings to the clinical setting, we developed a nonhuman primate model of perinatal asphyxia, using in utero umbilical cord occlusion (UCO) to produce moderate-to-severe HIE [4].

The nonhuman primate model of UCO-induced perinatal asphyxia has evolved over time with the goal of closely modeling the brain injury patterns and clinical manifestations of human neonates with moderate-tosevere HIE. Initially, UCO was increased from 12 to 15 min to produce a degree of perinatal asphyxia that modeled the newborn population targeted for neuroprotection in clinical trials of TH $[5,6]$. UCO for 15 min was associated with encephalopathy by physical exam and amplitude-integrated electroencephalography (aEEG) findings, abnormal EEG, progressive spasticity, cognitive delay, transient kidney and liver biochemical dysfunction, feeding delay, and neuronal degeneration with gliosis on immunohistochemistry [4]. In 4 animals with UCO for $15 \mathrm{~min}$, neurodevelopmental testing up to 4 months of age (approx. 16 human months) demonstrated severe motor impairment in 2 vehicle control animals compared to only mild motor impairment in 2 animals treated with erythropoietin $(5,000 \mathrm{U} / \mathrm{kg} /$ dose at birth and then $24 \mathrm{~h}$ later). However, magnetic resonance imaging (MRI) evidence of structural brain injury in the first 48-72 h of age or at 2 months of age was not detected in this model. In an effort to better replicate the morbidity of human neonates with moderate-to-se- vere HIE, the UCO was increased from 15 to $18 \mathrm{~min}$ $\left(\mathrm{UCO}_{18 \mathrm{~min}}\right)$ and neurodevelopmental follow-up was extended to 9 months of age (approx. 36 human months) [7]. All asphyxiated primates met the standard diagnostic criteria for human perinatal asphyxia (i.e., abnormal physical exam, acidosis, elevated lactate, large base deficits, and low APGAR scores). An examination of brain volume at 9 months versus at 1-3 days of age demonstrated decreased cerebellar (but not total brain, cortical, or basal ganglia) volume with $\mathrm{UCO}_{18 \text { min }}$ compared to controls. Improved fractional anisotropy, relative anisotropy, and volume ratios were apparent on early diffusion tensor imaging (at 24 and $72 \mathrm{~h}$ of age) in animals exposed to $\mathrm{UCO}_{18 \text { min }}$ treated with $\mathrm{TH}$ plus erythropoietin when compared to $\mathrm{UCO}_{18 \text { min }}$ saline animals. However, despite extending UCO to $18 \mathrm{~min}$, neither the watershed nor basal ganglia finding characteristic of human HIE brain injury was detected in this model at 1-3 days or at 6-9 months of age.

The UCO model has enabled us to associate HIE with poor developmental outcomes [7], directly test the effects of combined neurotherapeutic treatments on developmental brain injury [8], and characterize the circulating metabolome to identify potential biomarkers of HIE [9, 10]. In an effort to produce an MRI-detectable structural brain injury pattern consistent with patterns seen in human neonates, we further modified our model. When we attempted to induce structural brain injury by extending UCO beyond $18 \mathrm{~min}$ to $20 \mathrm{~min}$ (unpubl. data), the animal mortality rate became unacceptable. Therefore, we considered postnatal factors present in newborns with HIE that might contribute to brain injury. Human newborns exposed to perinatal events resulting in HIE are often subjected to additional stressors postnatally that might aggravate their condition, such as bradycardia, intermittent apnea, and mechanical ventilation. We present evidence showing that animals subjected to in utero UCO followed by prolonged ventilation and intermittent apnea exhibit patterns of injury in the basal ganglia, thalamus, and brain stem, that are precisely comparable to the postmortem injury effects observed in human neonates with severe HIE [11].

\section{Methods and Animals}

The Animal Care and Use Committees at the University of Washington in accordance with U.S. NIH guidelines approved all experimental procedures. An overview of the experimental UCO model used to produce HIE in Macaca nemestrina is provided in Figure 1.
108

Dev Neurosci 2017;39:107-123

DOI: $10.1159 / 000456658$
McAdams/McPherson/Kapur/Juul 


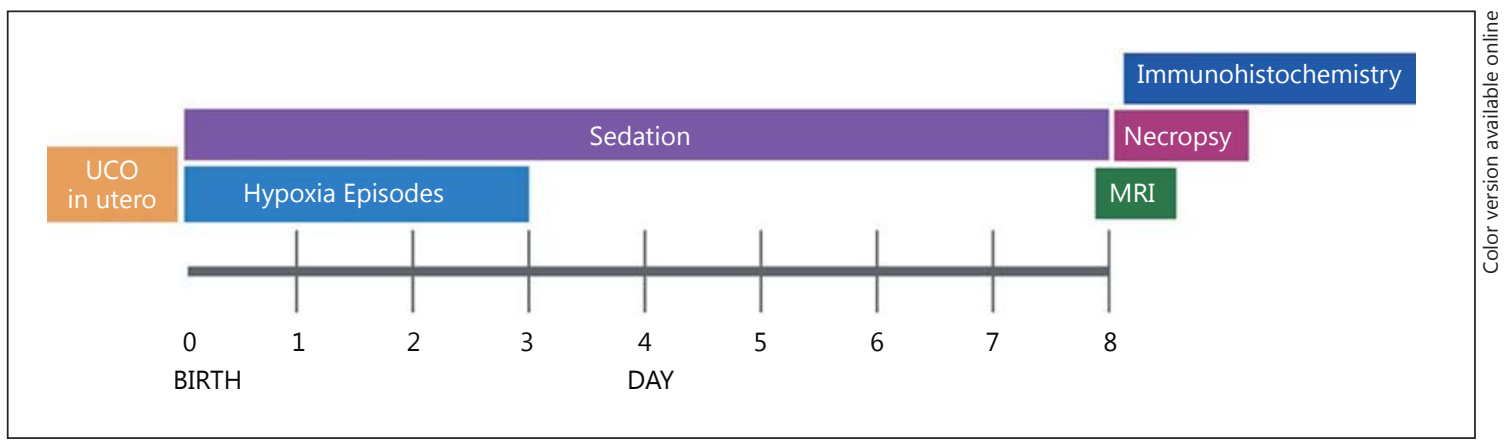

Fig. 1. An overview of the procedures and assessments for the nonhuman primate model of perinatal asphyxia. Animals received sedative infusions with either morphine $(n=2)$ or dexmedetomidine $(n=2)$, beginning at $6 \mathrm{~h}$ of age. Hypoxia episodes were induced during the first 3 days of age by exposing animals to $8 \% \mathrm{O}_{2}$ for 3 min to simulate apnea (range 6-21 episodes/animal). UCO, umbilical cord occlusion.

\section{Delivery and Resuscitation}

Four M. nemestrina (pigtailed macaques) were delivered by hysterotomy under maternal general anesthesia (sevoflurane) $9 \pm$ 2 days prior to term (173 days). One week of nonhuman primate life approximates to 1 month of human life, so these animals are comparable to late preterm infants at birth. After incising the uterus, the umbilical cord was exteriorized while keeping amniotic fluid and the fetus inside. To simulate perinatal asphyxia, the umbilical cord was clamped for $18 \mathrm{~min}$ and a 2.5 -Fr umbilical arterial catheter was inserted to permit all infusions and blood sampling. After delivery, animals were weighed and stabilized by a team of neonatologists using standardized neonatal resuscitation principles. Resuscitation included using endotracheal intubation, positive-pressure ventilation, chest compressions, and bolus epinephrine as needed. A heating pad, radiant warmer, and polyethylene sheet provided thermal support. APGAR scores were assessed at 1, 5, 10, and $20 \mathrm{~min}$. Subdermal scalp electrodes were installed to record aEEG for $24 \mathrm{~h}$. Animals were then moved into a customized thermal-neutral incubator and pulse oximetry and rectal temperature were monitored. A Babylog 8000 ventilator (Dräger, Lübeck, Germany) with humidifier, a Brainz BRM3 monitor (Natus Medical Inc., Pleasanton, CA, USA), infusion pumps, medical air/oxygen tanks, and a battery with a $120-\mathrm{V}$ AC inverter were mounted directly on the incubator to enable temporary portable operation.

\section{Animal Care}

Two infusion pumps provided parenteral nutrition and sedation. The parenteral nutrition mixtures contained dextrose and 2\% amino acids and electrolytes. Dextrose concentration (6-12\%), electrolytes and infusion rate were adjusted individually, based on monitoring. Animals were initially bolused with either morphine $(100 \mu \mathrm{g} / \mathrm{kg})$ or dexmedetomidine (DEX; $2 \mu \mathrm{g} / \mathrm{kg})$ at $1 \mathrm{~h}$ and again at $6 \mathrm{~h}$ of age. Sedative infusions $(1 \mathrm{~mL} / \mathrm{h})$ began at $6 \mathrm{~h}$ of age and were formulated in a solution of $6 \%$ dextrose and $2 \%$ protein to deliver $20 \mu \mathrm{g} / \mathrm{kg} / \mathrm{h}$ of morphine or $0.3 \mu \mathrm{g} / \mathrm{kg} / \mathrm{h}$ DEX based on the birth weight. Animals remained continuously sedated and received parenteral nutrition until necropsy on day 8 . Sedation scoring was performed every $6 \mathrm{~h}$, beginning at $6 \mathrm{~h}$ of age, and using an escalating 1-4 ordinal scale to assess sleep, response to touch, arousal, and tone. Animals exhibiting clinical seizure activity were administered doses of phenobarbital $(5 \mathrm{mg} / \mathrm{kg})$ until the seizure activity stopped.

\section{Postnatal Intermittent Hypoxia Exposure}

To simulate apnea with the intent of exacerbating the severity of HIE, animals were exposed to up to 8 daily episodes of hypoxia for the first 3 days of age as tolerated. Intubated animals were hand-ventilated with $8 \% \mathrm{O}_{2}$ for $3 \mathrm{~min}$, followed by $100 \% \mathrm{O}_{2}$ as needed for recovery. Heart rate and oxygen saturation $\left(\mathrm{SpO}_{2}\right)$ using an N-595 pulse oximeter (Nellcor, Pleasanton, CA, USA) were monitored and recorded during hypoxia exposure and recovery. The duration and frequency of hypoxia episodes were reduced individually for sensitive animals exhibiting poor tolerance (e.g., severe bradycardia or hypoxia with a slow return to baseline).

\section{Laboratory Analyses}

Clinical arterial blood gases were monitored as clinically indicated, using a portable blood gas processor (iSTAT, Abaxis, Union City, CA, USA). Blood samples $(0.4 \mathrm{~mL})$ for sedative pharmacokinetics and metabolomic measures were collected at $0,0.25,0.5,1$, $3,6,6.25,48,72$, and $120 \mathrm{~h}$ after the first sedative dose. Blood samples were collected in EDTA-coated tubes and spun at $1,000 \mathrm{~g}$ for $10 \mathrm{~min}$, and the plasma was aliquoted and frozen at $-80^{\circ} \mathrm{C}$. Plasma concentrations of morphine and DEX were determined by ELISA.

\section{MRI and Spectroscopy}

At 8 days of age, animals underwent MRI and magnetic resonance spectroscopy (MRS) brain imaging followed by necropsy as previously described [7]. A single, nonasphyxiated $M$. nemestrina primate delivered by cesarean section, but with no exposure to UCO or prolonged sedation, also underwent MRI/MRS at 8 days of age. This nonasphyxiated animal was included for the comparative control MRI/MRS data only, since it did not undergo necropsy at day 8 . MRI sequences included magnetization-prepared rapid gradient echo (MP-RAGE) high-resolution T1-weighted imaging and single-voxel proton spectroscopy (MRS) was obtained on a Phillips Achieva 3.0-tesla magnet with an X-series Quasar Dual gradient system. Custom-fit 8-channel array head coils were 
used. For structural analysis, a 3-dimensional, high-resolution, T1-weighted MP-RAGE protocol was used. For biochemical analysis, single-voxel MRS was acquired using a point-resolved spectroscopy pulse sequence centered on a $10 \times 10 \times 10 \mathrm{~mm}$ voxel on the right thalamus. The MP-RAGE sequence was reconstructed in real time to guide MRS voxel placement. Acquisition parameters included: TR $=2,000 \mathrm{~ms}$; TE at 6 different echo times $(32,45,65$, 80,100 , and $150 \mathrm{~ms}$ ); 2,048 complex free induction decay points, and $2,000 \mathrm{~Hz}$ spectral width. Absolute concentrations of shortecho (at TE $=32 \mathrm{~ms}$ ) metabolites: $N$-acetyl aspartate (NAA), creatine $(\mathrm{Cr})$, choline, myoinositol, glutamate, and glutamate + glutamine were calculated using LCModel [12]. Absolute concentrations are reported in units that approximate to millimolar concentrations. Partial volume corrections were made using the FSL segmentation software called FAST (Oxford, UK).

A historical cohort of 25 animals delivered by cesarean section at $169 \pm 2$ weeks' gestation, i.e. 12 control animals ( 4 male, 8 female), and 13 animals ( 6 male, 7 female) that underwent UCO for $15(n=5)$ to $18(n=8)$ min $\left(\mathrm{UCO}_{15-18 \mathrm{~min}}\right)$, was included in this study for MRS comparison purposes. These 25 animals had MRS performed between 24 and $72 \mathrm{~h}$ of age, using the abovementioned protocol. The $\mathrm{UCO}_{15-18 \mathrm{~min}}$ animals received saline treatment at 30 min, $24 \mathrm{~h}, 48 \mathrm{~h}$, and 7 days of age as part of a study assessing the safety and effectiveness of erythropoietin plus $\mathrm{TH}$ in animals with HIE [8].

\section{Transmission Electron Microscopy}

After perfusion, brains were removed and biopsy punches from the corpus callosum were collected and processed for transmission electron microscopy (TEM) using $0.1 \mathrm{M}$ sodium cacodylate solution containing $4 \%$ paraformaldehyde/ $2 \%$ glutaraldehyde, cacodylate solution with $1 \%$ osmium tetroxide, serial ethanol dehydration, propylene oxide/EMbed 812 medium, and then embedded and baked. Semi-thick sections were cut and stained with toluidine blue, before ultrathin sections (70 $\mathrm{nM}$ ) were prepared on grids and stained with lead citrate. Multiple TEM images were captured at high $(\times 30,000)$ and low $(\times 5,000)$ magnifications (JEOL $1230 \mathrm{mi}-$ croscope, JEOL USA, Peabody, MA, USA). Captured TEM images from the 4 animals were reviewed in a blinded manner by a veterinary pathologist and compared to HE slides, and TEM images were assessed semiquantitatively for the severity of white matter injury, based on the presence of perinuclear vacuolation and/or axonal swelling. Artifact was present on the TEM images from animal 4, which confounded critical analysis.

\section{Histology and Immunohistochemistry of Brain Tissue}

Perfusion-fixed brain tissues were embedded in paraffin and $4-\mu \mathrm{m}$-thick sections from the brain stem, thalamus, and basal ganglia were stained with hematoxylin and eosin (H\&E) or immunostained with the Ventana BenchMark ULTRA automated immunostainer (Ventana Medical Systems, Tucson, AZ, USA). Singletarget peroxidase-based labeling using anti-GFAP (1:400, DakoCytomation, Denmark) or anti-CD163 (1:200, Vector Laboratories, Burlingame, CA, USA) primary antibodies was performed.

Brain stem tissues were embedded in paraffin and the 4- $\mu \mathrm{m}$ thick sections from the pons and medulla were H\&E-stained or immunostained with the Ventana BenchMark ULTRA according to the manufacturer's instructions. Sections were subjected to an antigen retrieval process of $8 \mathrm{~min}$ with the Ventana Cell Condi- tioner 1, followed by GFAP detection using an anti-GFAP antibody (Predilute, ready to use, Ventana Medical Systems).

Staining for Nogo-A, a negative regulator of neuronal growth that has been shown to limit neural plasticity and recovery from brain injury [13], was performed, to determine if this signaling protein was present in the brain injury related to UCO plus postnatal hypoxia exposure. Dual immunofluorescence to localize GFAP and Nogo-A was performed on representative paraffin sections from the brains of each experimental animal and 2 controls. For the controls, brain tissue was obtained from $2 \mathrm{M}$. nemestrina fetuses delivered by cesarean section (at 142 and 145 days' gestation, respectively), immediately euthanized by a barbiturate overdose, followed by exsanguination and fetal necropsy with tissue fixation in $10 \%$ neutral-buffered formalin. Coronal sections of the cerebral hemisphere at the level of the rostral lenticular nucleus (globus pallidus and putamen) were preincubated in $0.1 \mathrm{M}$ citrate buffer $(20 \mathrm{~min}$ in a rice-steamer), blocked with $5 \%$ goat serum $/ 0.3 \%$ Triton $\mathrm{X} /$ phosphate-buffered saline for $2 \mathrm{~h}$, incubated overnight in rabbit antiNogo-A (1:1,000; Abcam, Cambridge, MA, USA) and mouse antiGFAP (1:400; DakoCytomation), washed and incubated in secondary antibodies (1:500; anti-rabbit-Cy3, Jackson ImmunoResearch, West Grove, PA, USA and anti-mouse-Dylight 488, Vector Laboratories) and counterstained with DAPI. Digital images of the labeling were captured using Elements software (Nikon Corp. Tokyo, JP), with uniform capture settings used for all sections.

\section{Plasma Metabolomics}

Plasma metabolites were extracted, derivatized and detected using 2-dimensional gas chromatography coupled with time-offlight mass spectrometry (GC $\times$ GC-TOFMS), as previously described [10]. Metabolites were identified using Chroma TOF software (LECO Corp., St. Joseph, MI, USA) and analyzed with a parallel factor analysis (PARAFAC) algorithm to determine the $\mathrm{m} / z$ peak signal intensity normalized to total ion current. The signal ratio method was used to select the top 15 candidates for statistical comparisons.

\section{Statistics}

For parametric data, one-way ANOVA followed by post hoc tests (SPSS, Chicago, IL, USA) or unpaired $t$ tests were performed as indicated in the text. ANOVA data are presented as means with standard error (SEM), for which post hoc tests included the $t$ test or the Dunnett test for multiple comparisons. In addition, the Spearman rank-order correlation coefficients were calculated to compare nonparametric ordinal data as described. All comparisons were two-tailed with $a \leq 0.05$.

\section{Results}

All 4 animals delivered after $\mathrm{UCO}_{18}$ min were flaccid, unresponsive to stimulation, and had no spontaneous respiration. All animals received positive-pressure ventilation and chest compressions during resuscitation, and animal 2 received epinephrine for a low heart rate unresponsive to ventilation. Table 1 describes the birth indices including weight, sex, and number of days preterm as well 
Table 1. Neonatal measurements collected during resuscitation of 4 primates delivered after in utero UCO to induce HIE

\begin{tabular}{|c|c|c|c|c|c|c|c|c|c|c|c|c|c|}
\hline \multirow{2}{*}{$\begin{array}{l}\text { Animal } \\
\text { No. }\end{array}$} & \multirow{2}{*}{$\begin{array}{l}\text { Birth } \\
\text { weight, g }\end{array}$} & \multirow[t]{2}{*}{ Sex } & \multirow{2}{*}{$\begin{array}{l}\text { Number of } \\
\text { days preterm }\end{array}$} & \multirow[t]{2}{*}{$\mathrm{pH}$} & \multirow[t]{2}{*}{$\mathrm{BE}$} & \multirow[t]{2}{*}{$\mathrm{pCO}_{2}$} & \multirow[t]{2}{*}{$\mathrm{pO}_{2}$} & \multirow{2}{*}{$\mathrm{HCO}_{3}$} & \multirow[t]{2}{*}{ Lactate } & \multicolumn{4}{|c|}{ APGAR scores } \\
\hline & & & & & & & & & & 1 & 5 & 10 & 20 \\
\hline 1 & 561 & M & -10 & 6.9 & -20 & 67.9 & 94 & 13 & 14.8 & 1 & 2 & 2 & 5 \\
\hline 2 & 459 & M & -11 & 7.1 & -19 & 36.3 & 279 & 10.9 & 13.2 & 1 & 3 & 3 & 3 \\
\hline 3 & 526 & $\mathrm{~F}$ & -7 & 7.1 & -19 & 29.8 & 87 & 10.1 & 12.7 & 1 & 2 & 4 & 4 \\
\hline 4 & 461 & $\mathrm{~F}$ & 7 & 6.9 & -25 & 40.1 & 232 & 7.7 & 17.8 & 1 & 3 & 4 & 4 \\
\hline
\end{tabular}

Blood gas and APGAR scores are all indicative of perinatal hypoxia-ischemia. UCO, umbilical cord occlusion; HIE, hypoxic-ischemic

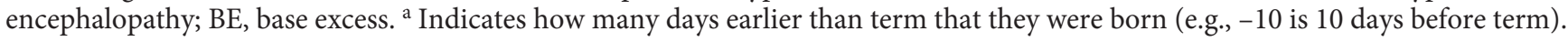

as initial blood gas values and APGAR scores that were indicative of perinatal asphyxia.

The aEEG tracings (not shown) from all animals showed burst suppression for $4-5 \mathrm{~h}$, with a subsequent elevation from baseline to normal at around $6 \mathrm{~h}$ of age after UCO. Three of the 4 animals exhibited electrographic and clinical seizures, with the onset ranging from 9 to $26 \mathrm{~h}$. Seizures were treated with phenobarbital and lasted 1-2 days in 2 animals (animals 2 and 3), but persisted for 7 days in 1 animal (animal 1).

$\mathrm{SpO}_{2}$ response to $3 \mathrm{~min}$ of hypoxia exposure were lower (unpaired $t$ test MS vs. DEX at $3 \mathrm{~min}$ ) in the morphinetreated animals (animals 1 and 2) than in the DEX-treated animals (animals 3 and 4) (Fig. 2). Neither heart rate response nor sedation scores appeared significantly different in relation to sedative treatment. At $3 \mathrm{~min}$ after hypoxia exposure, the mean $\mathrm{SpO}_{2}$ was $23 \pm 12 \%$ in the morphinetreated versus $63 \pm 5 \%$ in the DEX-treated animals. The $\mathrm{SpO}_{2}$ returned to $>98 \%$ within 1 min of recovery in all animals. In contrast to the consistent pattern of desaturation, the heart rate responses did not vary uniformly during hypoxia. In addition, the animals' tolerance of the postnatal hypoxia varied, so the number of episodes was adjusted individually (total episodes over 3 days: 23 for animal 1, 6 for animal 2, 13 for animal 3, and 21 for animal 4).

A single bolus of sedative (morphine or DEX) was given after resuscitation, and a second bolus followed by sedative infusion was initiated at $6 \mathrm{~h}$ of age and maintained until necropsy on day 9. Figure 3 presents the corresponding pharmacokinetic data showing plasma concentrations of morphine and DEX at scheduled time points. A battery of 4 sedation scores (sleep, arousal, touch response, and tone) were recorded every $6 \mathrm{~h}$ for 7 days, but there were no differences for any of the scores (data not shown). There were no differences in adverse events based on sedation.

HIE Model in Nonhuman Primates

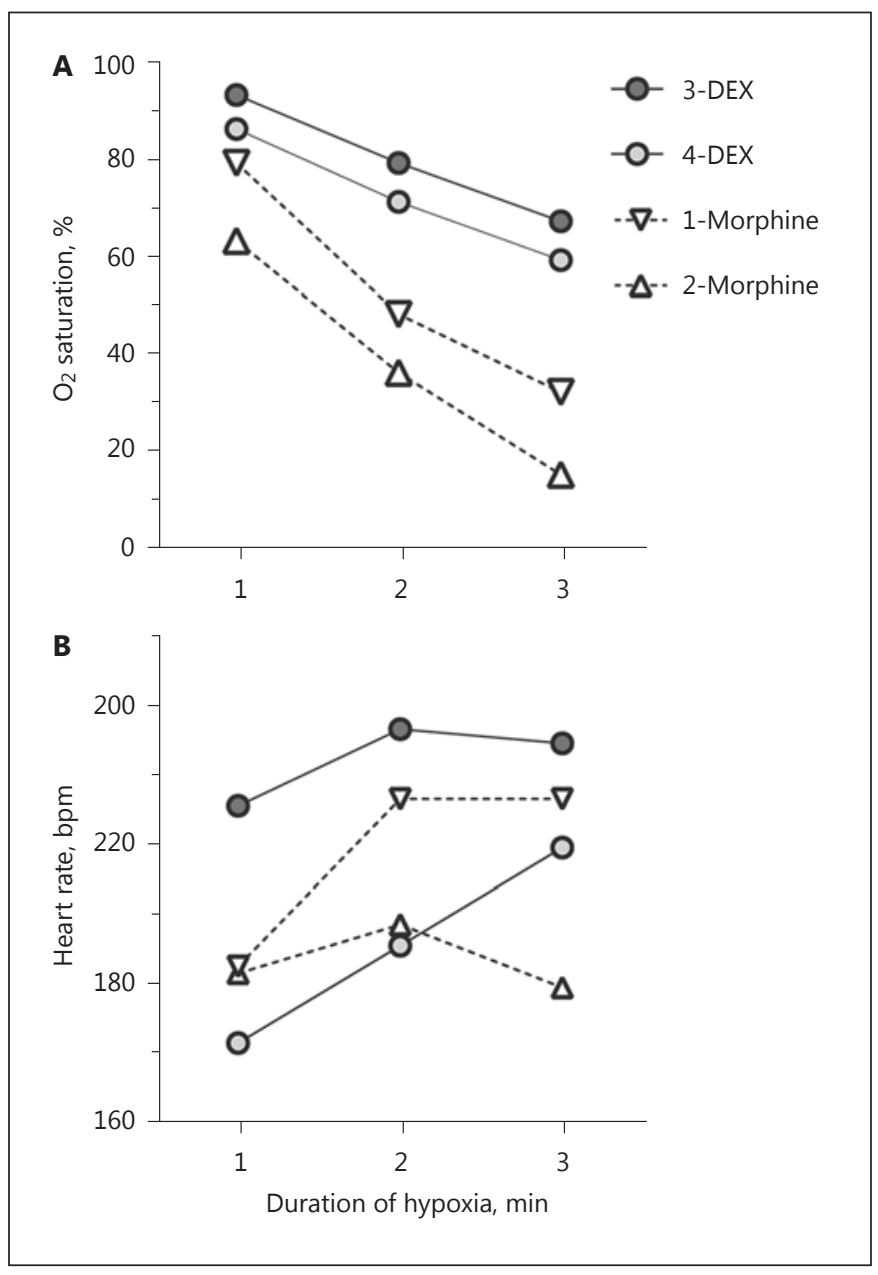

Fig. 2. Plots show the time course of changes in $\mathrm{SpO}_{2}(\mathbf{A})$ and heart rate (B) recorded from individual animals (1-4) during exposure to $8 \% \mathrm{O}_{2}$ (hypoxia) to simulate apnea for $3 \mathrm{~min}$. Data points are the average of all measurements for each animal from repeated exposures (range 6-21 episodes/animal) performed during the first 3 days of age. Animals 1 and 2 received continuous morphine at $20 \mu \mathrm{g} / \mathrm{kg} / \mathrm{h}$ and animals 3 and 4 received continuous dexmedetomidine (DEX) at $0.3 \mu \mathrm{g} / \mathrm{kg} / \mathrm{h}$.

Dev Neurosci 2017;39:107-123

DOI: $10.1159 / 000456658$ 


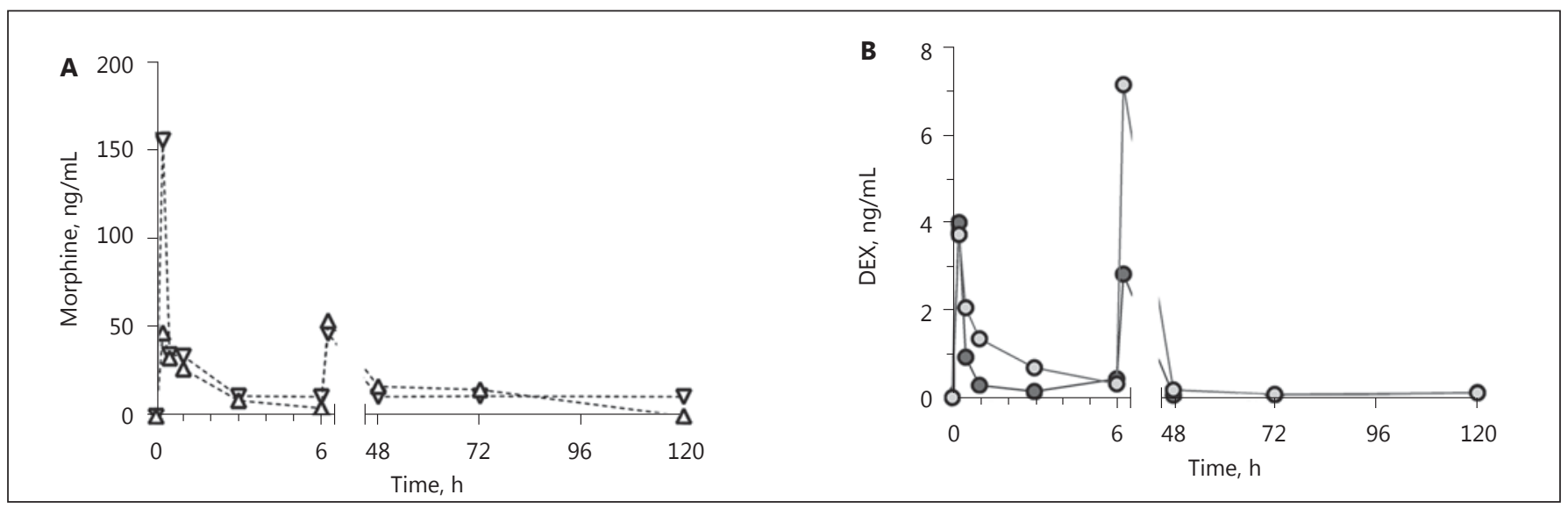

Fig. 3. Plots show the plasma concentrations of morphine (triangles, $\mathbf{A}$ ) in animals 1 and 2 or dexmedetomidine (DEX) in animals 3 (black circles) and 4 (gray circles) (B) measured at scheduled intervals. Half-life $\left(t_{1 / 2}\right)$ and rate constant $(\kappa)$ were calculated using data for the first $6 \mathrm{~h}$, after which time a second bolus was admin- istered and continuous infusions were initiated (1-phase decay, morphine: $t_{1 / 2}=7.5 \mathrm{~min}, \kappa=5.5$; DEX: $\left.t_{1 / 2}=9.6 \mathrm{~min}, \kappa=4.2\right)$. Dosing for morphine was $100 \mu \mathrm{g} / \mathrm{kg}$ bolus (at 1 and $6 \mathrm{~h}$ ) and then $20 \mu \mathrm{g} / \mathrm{kg} / \mathrm{h}$ after $6 \mathrm{~h}$; for DEX, it was $2 \mu \mathrm{g} / \mathrm{kg}$ bolus (at 1 and $6 \mathrm{~h}$ ) and then $0.3 \mu \mathrm{g} / \mathrm{kg} / \mathrm{h}$ infusion after $6 \mathrm{~h}$.
Fig. 4. MRIs recorded from 4 individual 8-day-old primates exposed to umbilical cord occlusion for 18 min plus postnatal mechanical ventilation and hypoxic episodes while under continuous sedation with either morphine or dexmedetomidine. The numbers $1-4$ indicate the animal that corresponds to the T2-weighted and FLAIR images in each column. T2-weighted and FLAIR MRI revealed bilateral hyperintensity present in the posterior thalamus of 3 of the 4 animals (highlighted by arrowheads). In addition, animal 4 has evidence of unilateral hyperintensity in the putamen nucleus (the anterior arrow).

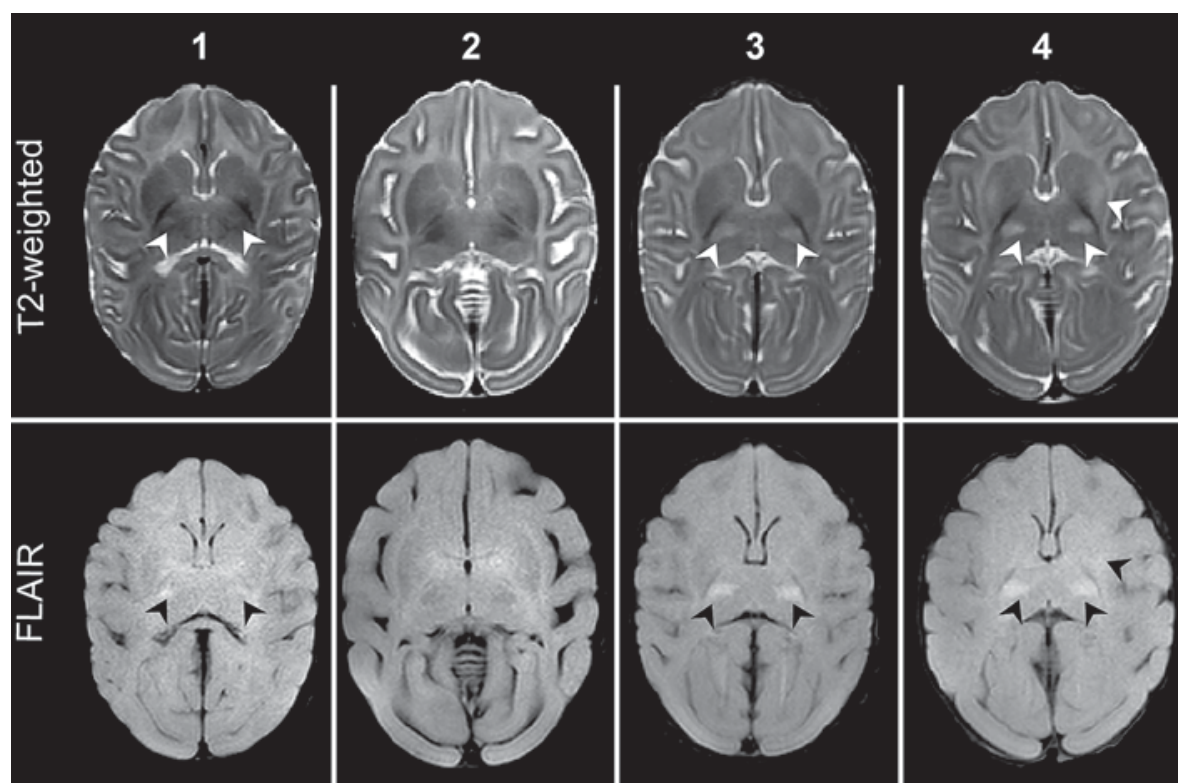

\section{$M R I$ and $M R S$}

The MRI and MRS data were evaluated by a boardcertified neurologist and were compared with data from a contemporary nonstudy primate. Figure 4 contains T2weighted and fluid-attenuated inversion recovery (FLAIR) MRIs from each UCO animal collected just prior to necropsy on day 8 of age. MRI detected bilateral ventral posterolateral thalamus injury, which was evident in 3 of the 4 UCO animals on both T2-weighted and FLAIR imaging (Fig. 4). The control animal had normal
MRI findings (images not shown). Diffusion-weighted images were normal for all animals (not shown).

The MRS data on the $4 \mathrm{UCO}_{18 \text { min }}$ and the single nonasphyxiated control animal are presented in Table 2. Historical comparison data were used to investigate potential MRS metabolite differences related to $\mathrm{UCO}_{18 \text { min }}$ with and without postnatal hypoxia exposure. We previously reported MRS data obtained at $24-72 \mathrm{~h}$ of age from 25 animals delivered by cesarean section, including 12 control animals and 13 animals that underwent $\mathrm{UCO}_{15-18} \mathrm{~min}$ 
Table 2. MRS data on concentrations at 8 days of age in animals who underwent UCO for 18 min plus episodes of postnatal hypoxia exposure compared to an age-matched control animal and also the historical UCO animals (and controls)

\begin{tabular}{lllllllllll}
\hline & Cho & Cr & NAA & Macm & Ins & Glul & Glx & Cho/Cr & NAA/Cho & NAA/Cr \\
\hline Animal 1 & 1.36 & 5.91 & 4.09 & 13.02 & 5.83 & 2.99 & 5.93 & 0.23 & 3.01 & 0.69 \\
Animal 2 & 1.70 & 5.98 & 4.09 & 13.41 & 5.32 & 2.52 & 7.37 & 0.28 & 2.41 & 0.68 \\
Animal 3 & 1.48 & 6.5 & 3.74 & 12.87 & 5.62 & 2.74 & 8.99 & 0.23 & 2.53 & 0.58 \\
Animal 4 & 1.35 & 5.58 & 3.58 & 16.74 & 5.43 & 2.75 & 7.88 & 0.24 & 2.65 & 0.64 \\
Control & 1.55 & 4.82 & 4.23 & 7.89 & 4.19 & 3.20 & 8.87 & 0.32 & 2.72 & 0.88 \\
\hline UCO + PH $^{\mathrm{a}}$ & $1.47 \pm 0.08$ & & $2.65 \pm 0.13$ & & & & & $0.25 \pm 0.01$ & $2.65 \pm 0.13$ & $0.65 \pm 0.03 *$ \\
UCO $_{18 \text { min }}$ b & $1.63 \pm 0.07$ & & $4.03 \pm 0.10$ & & & & & $0.30 \pm 0.01$ & $2.50 \pm 0.13$ & $0.73 \pm 0.02$ \\
Controls $^{\mathrm{c}}$ & $1.60 \pm 0.05$ & & $4.30 \pm 0.09$ & & & & & $0.29 \pm 0.01$ & $2.79 \pm 0.08$ & $0.79 \pm 0.02$ \\
\hline
\end{tabular}

$\mathrm{PH}$, postnatal hypoxia; Cho, choline; Cr, creatine; NAA, N-acetyl aspartate; Macm, macromolecules; Ins, myoinositol; Glu1, glutamate-1; Glx, glutamate + glutamine. ${ }^{\star} p=0.008$ based on one-way ANOVA post hoc testing, UCO + PH compared to UCO and controls.

a Animals 1-4 of this study that underwent UCO for 18 min plus episodes of postnatal hypoxia.

${ }^{\mathrm{b}}$ Historical comparison data obtained at $24-72 \mathrm{~h}$ of age from 13 animals who underwent UCO for $18 \mathrm{~min}$ [8].

${ }^{\mathrm{c}}$ Historical comparison data obtained at $24-72 \mathrm{~h}$ of age from 12 controls [8].

${ }^{\mathrm{a}-\mathrm{c}}$ Values show mean \pm SEM.

Table 3. Brain histopathology findings of 4 nonhuman primates exposed to in utero UCO to induce HIE and postnatal hypoxia episodes with necropsy on day 8 of age

\begin{tabular}{|c|c|c|c|c|c|c|}
\hline $\begin{array}{l}\text { Animal } \\
\text { No. }\end{array}$ & Thalamus and striatum & $\begin{array}{l}\text { Cerebral white } \\
\text { matter }\end{array}$ & $\begin{array}{l}\text { Cerebral } \\
\text { gray matter }\end{array}$ & $\begin{array}{l}\text { Hippo- } \\
\text { campus }\end{array}$ & Cerebellum $^{1}$ & Brain stem \\
\hline 1 & $\begin{array}{l}\text { Acute neuronal necrosis and } \\
\text { gliosis in ventrolateral } \\
\text { thalamus; putamen/globus } \\
\text { pallidus not affected }\end{array}$ & n.d.a. & n.d.a. & n.d.a. & n.d.a. & $\begin{array}{l}\text { diffuse gliosis, but no } \\
\text { obvious apparent } \\
\text { neuronal loss }\end{array}$ \\
\hline 2 & $\begin{array}{l}\text { Neuronal injury/loss and } \\
\text { severe gliosis in small portion } \\
\text { of ventrolateral thalamus; } \\
\text { putamen/globus pallidus not } \\
\text { affected }\end{array}$ & $\begin{array}{l}\text { mild deep white } \\
\text { matter gliosis }\end{array}$ & n.d.a. & n.d.a. & n.d.a. & $\begin{array}{l}\text { large foci of neuronal } \\
\text { injury/loss and severe } \\
\text { gliosis in tegmentum of } \\
\text { midbrain and pons and } \\
\text { lateral medulla }\end{array}$ \\
\hline 3 & $\begin{array}{l}\text { Neuronal injury/loss and } \\
\text { severe gliosis in large portion } \\
\text { of ventrolateral thalamus and } \\
\text { putamen/globus pallidus }\end{array}$ & $\begin{array}{l}\text { mild deep white } \\
\text { matter gliosis }\end{array}$ & n.d.a. & n.d.a. & n.e. & $\begin{array}{l}\text { large foci of neuronal } \\
\text { injury/loss and severe } \\
\text { gliosis in tegmentum } \\
\text { of midbrain and pons } \\
\text { and lateral medulla }\end{array}$ \\
\hline 4 & $\begin{array}{l}\text { Neuronal injury/loss and } \\
\text { severe gliosis in large portion } \\
\text { of ventrolateral thalamus and } \\
\text { putamen/globus pallidus }\end{array}$ & $\begin{array}{l}\text { mild deep white } \\
\text { matter gliosis }\end{array}$ & n.d.a. & n.d.a. & $\begin{array}{l}\text { Purkinje cell } \\
\text { loss with } \\
\text { Bergman } \\
\text { gliosis }\end{array}$ & $\begin{array}{l}\text { large foci of neuronal } \\
\text { injury/loss and severe } \\
\text { gliosis in tegmentum } \\
\text { of midbrain and pons } \\
\text { and lateral medulla }\end{array}$ \\
\hline
\end{tabular}

UCO, umbilical cord occlusion; HIE, hypoxic ischemic encephalopathy; n.d.a., no diagnostic alterations; n.e., not evaluated.

${ }^{1}$ Only a small portion of cerebellum was sampled. 


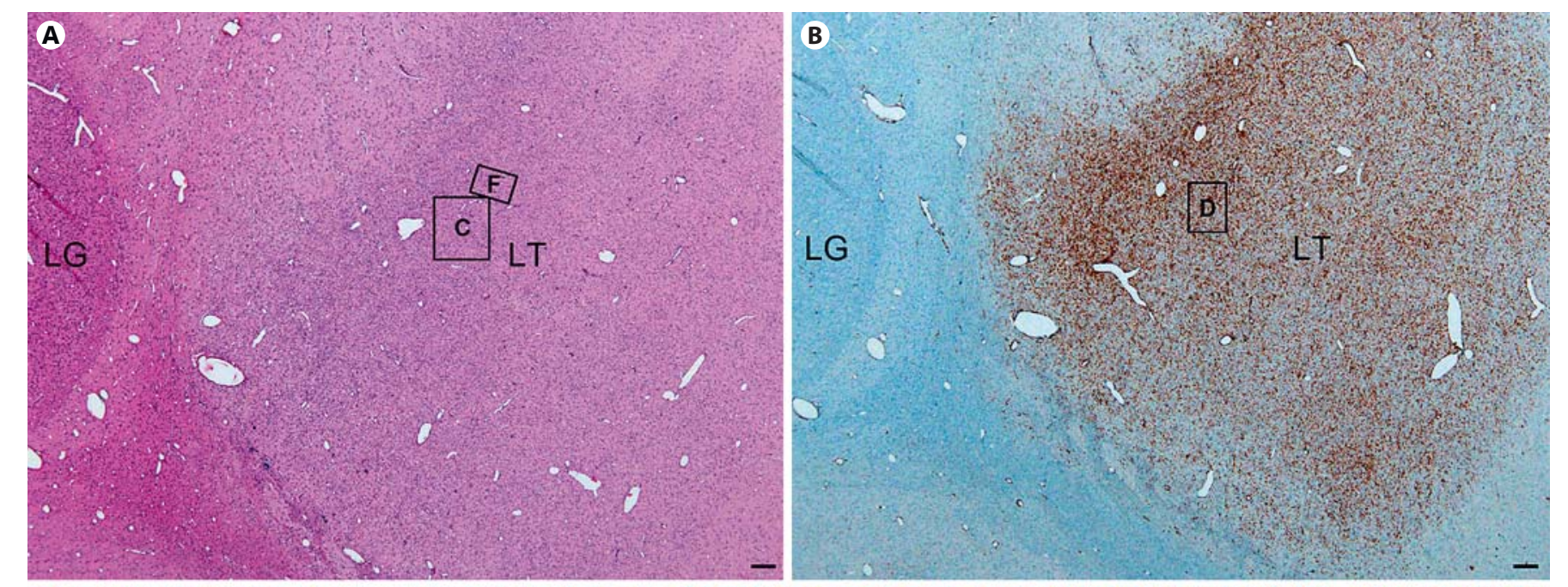

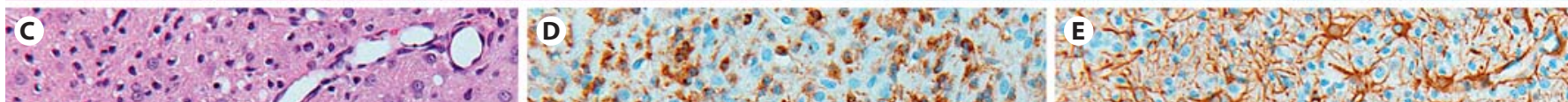

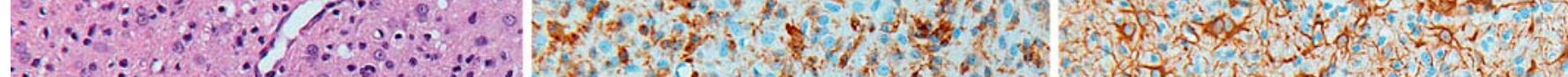

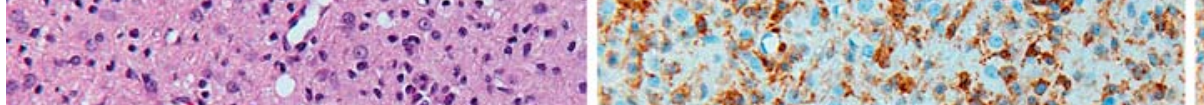

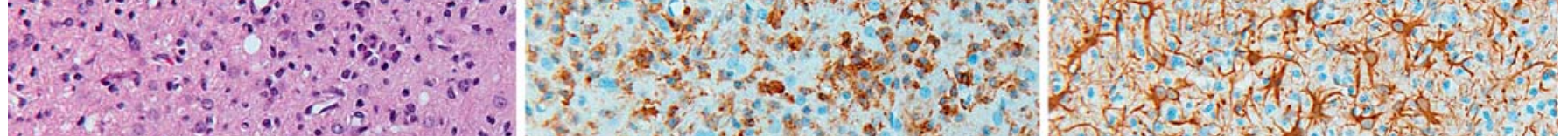

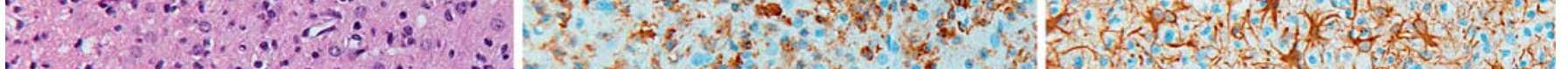

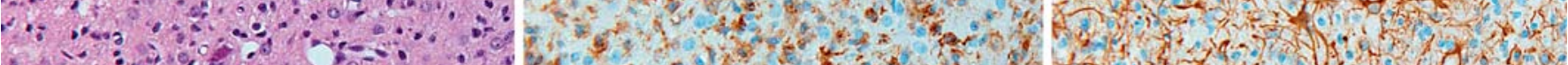

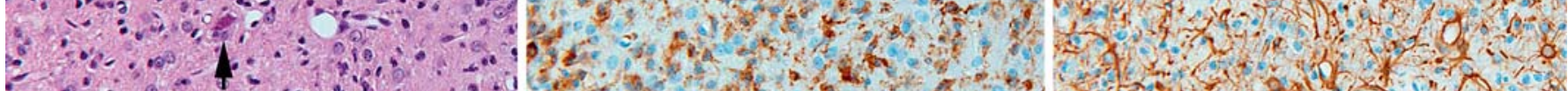

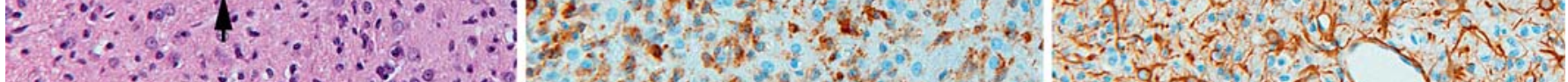

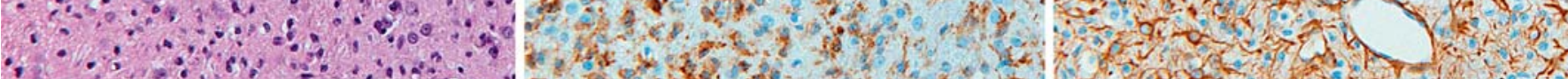

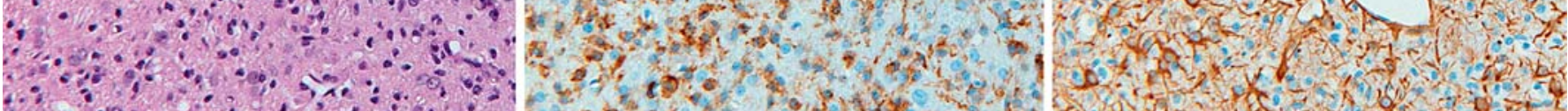

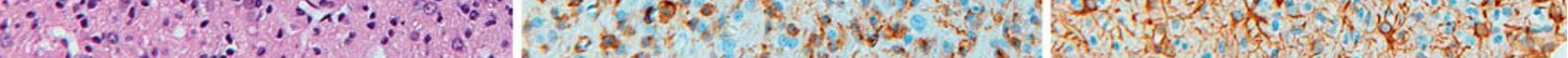

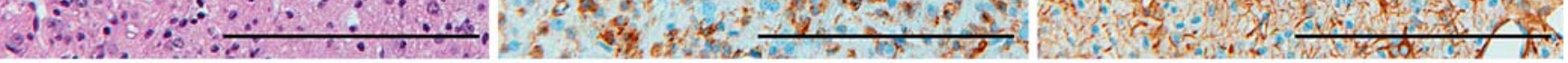

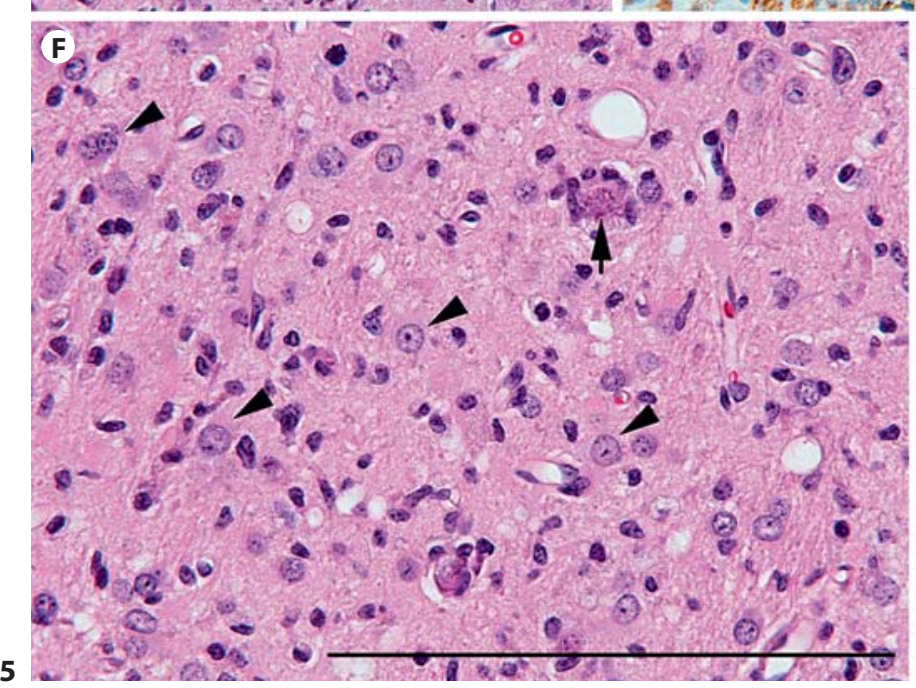

5

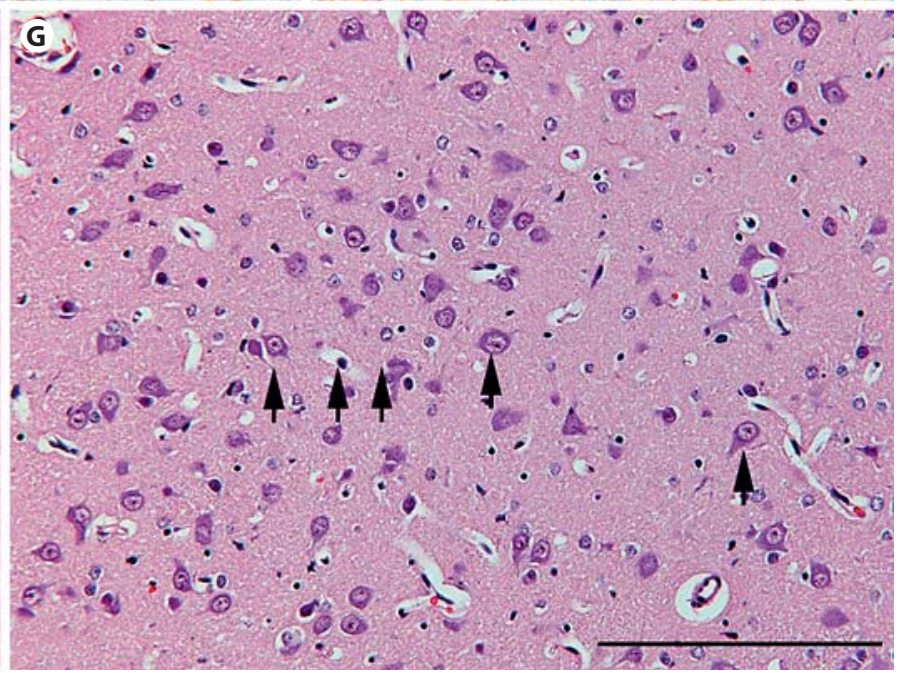

(For legend see next page.)
Dev Neurosci 2017;39:107-123

DOI: $10.1159 / 000456658$
McAdams/McPherson/Kapur/Juul 
without postnatal hypoxia exposure [8]. Similar to the animals in this study, this historical group also had MRS acquired with a voxel on the right thalamus. In the 4 animals exposed to $\mathrm{UCO}_{18}$ min plus postnatal hypoxia, the NAA/Cr ratio (mean \pm SEM, $0.65 \pm 0.03$ ) was lower than in the historical UCO animals $(0.73 \pm 0.02)$ and in the historical control $(0.79 \pm 0.02)$ animals $(p=0.008)$ (ANO$\mathrm{VA}+$ post hoc testing of study vs. control).

\section{Histology and Immunohistochemistry of Brain Tissue}

Coronal sections from the cerebral hemispheres of the UCO animals showed a similar pattern of histopathological changes with variable severity, and correlated well with MRI images. Foci of neuronal degeneration and hypercellularity due to reactive gliosis were present, particularly in the lateral thalamus, rostral caudate nucleus, and lenticular nucleus (globus pallidus and putamen) (Fig. 5A). Other regions, including the hippocampus, cortical gray and white matter, and most of the large white-matter tracts showed little or no gliosis and no obvious neuronal loss. However, mild increased gliosis in the corpus callosum was apparent in the more severely injured animals (animals 3 and 4). Cerebellar tissue was only available for animals 1,2 , and 4 . No cerebellar abnormalities were detected in animals 1 and 2, but animal 4 demonstrated Purkinje cell dropout and Bergmann gliosis. Immunostaining confirmed the accumulation of activated microglia (CD163+) and astrocytosis (GFAP-positive) at the sites of injury including the lateral thalamus, corresponding to the region of hyperintensity detected by MRI (Fig. 5B). These lesions were fairly discrete and bordered by minimally gliotic tissue, even in the most severely affected brains.

Grossly, the brain stems were normal, but gliosis was present in all 4 animals. Three cases (animals 2, 3, and 4) exhibited severe bilateral symmetric neuronal loss and gliosis in the dorsolateral tegmentum, paragigantocellularis lateralis, dorsal reticular nuclei, and gliosis in the nucleus tractus solitarius, dorsal motor nucleus $\mathrm{X}$, and inferior olive, but no pathology of the hypoglossal nucleus, white-matter tracts or vasculature. Figure 6 presents stained images from animal 3 and shows that subarach-
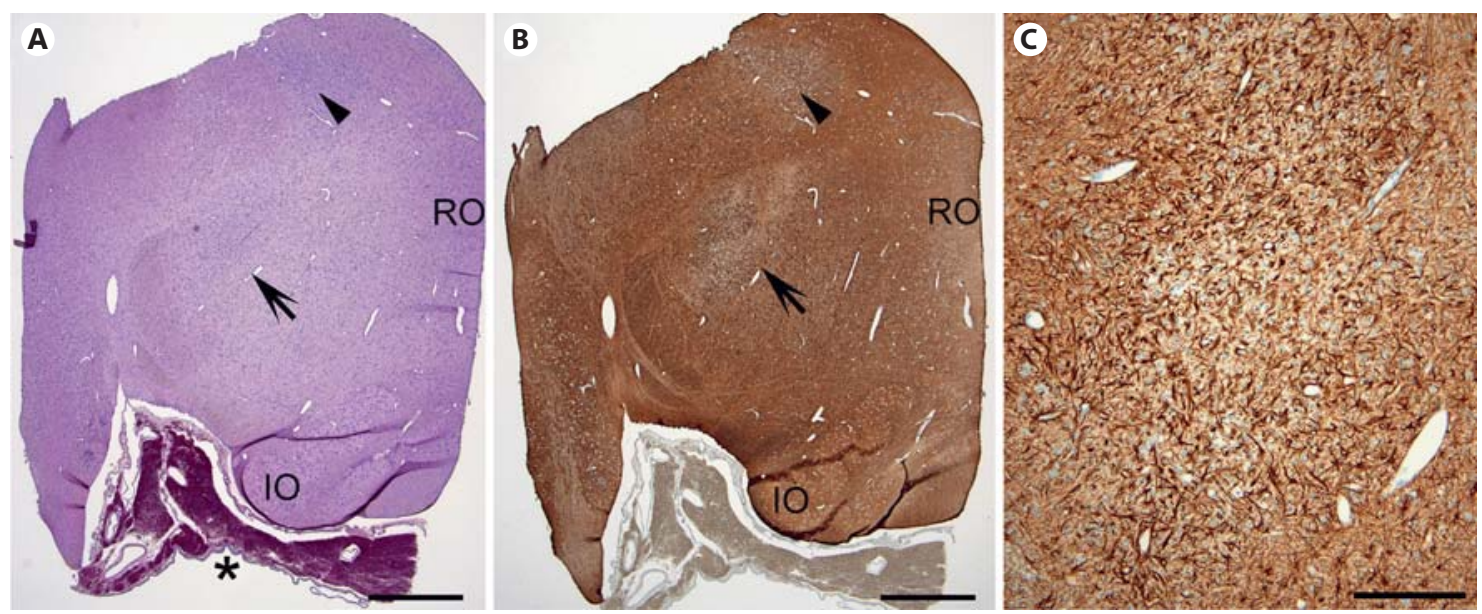

Fig. 6. Hemisected sections of medulla taken from animal 3 and labeled for the raphe obscurus (RO) and the inferior olive (IO). A low-power H\&E stain (A) and GFAP immunostain (B) reveal the area of the focal scarring in the nucleus tractus solitarius (NTS, arrowhead) and the reticular formation (arrow). An asterisk denotes the ventral subarachnoid hemorrhage. $\mathbf{C}$ A higher-magnification image depicting GFAP-immunopositive reactive astrocytes in the reticular formation derived from the region of the arrow-tip in $\mathbf{B}$. Scale bars, $1 \mathrm{~mm}(\mathbf{A}, \mathbf{B}), 200 \mu \mathrm{m}(\mathbf{C})$.
Fig. 5. Histological and immunostaining images from an infarct in the lateral thalamus (LT) of animal 4. H\&E. A A geographic zone of hypercellularity is evident in the lateral thalamus (boxes indicate regions of higher magnification displayed in $\mathbf{C}$ and $\mathbf{F}$ ), just medial to the lateral geniculate nucleus (LG). In this focus, neurons are lost or degenerating (arrows in $\mathbf{C}$ and $\mathbf{F}$ ) and reactive astrocytes (arrowheads) abound. B Adjacent sections demonstrate that the hypercellularity is due in part to infiltration (box indicates a region of higher magnification displayed in $\mathbf{D}$ ) by CD163-immunoreactive activated microglia and GFAP-immunopositive reactive astrocytes (E). G A histological field in the adjacent medial portion of the thalamus shows intact neurons (arrows) and a normal density of relatively inconspicuous, nonreactive astrocytes and microglia. Scale bars, $200 \mu \mathrm{m}$. 
Table 4. Mass spectral intensity values for metabolites in plasma from neonatal primates $(n=4)$ before and after UCO-induced HIE

\begin{tabular}{lccc}
\hline \multicolumn{4}{c}{ Postnatal age } \\
\cline { 2 - 4 } & $0 \mathrm{~h}$ & \multicolumn{3}{c}{} \\
& & & \\
& & \\
& & \\
Section A & & \\
$\quad$ Arachidonic acid & $5 \pm 1$ & $18 \pm 3^{* *}$ & $10 \pm 2$ \\
Fumaric acid & $3 \pm 0$ & $15 \pm 2^{* * *}$ & $7 \pm 1$ \\
Succinic acid & $11 \pm 5$ & $435 \pm 58^{* * *}$ & $19 \pm 2$ \\
Propanoic acid & $2,611 \pm 396$ & $4,089 \pm 202^{*}$ & $1,859 \pm 244$ \\
\hline Section B & \multicolumn{3}{c}{} \\
Myoinositol & $444 \pm 54$ & $834 \pm 63^{*}$ & $1,185 \pm 121^{* * *}$ \\
L-glutamate & $84 \pm 11$ & $203 \pm 10$ & $152 \pm 18^{*}$ \\
Choline & $21 \pm 5$ & $15 \pm 2$ & $54 \pm 11^{* * *}$ \\
Glycine & $74 \pm 8$ & $113 \pm 20$ & $230 \pm 50^{*}$ \\
L-serine & $147 \pm 39$ & $266 \pm 44$ & $447 \pm 89^{*}$ \\
Oleic acid & $125 \pm 27$ & $62 \pm 6$ & $322 \pm 62^{*}$ \\
Erythropentonic acid & $3 \pm 0$ & $5 \pm 1$ & $19 \pm 3^{* * *}$ \\
\hline Section C & \multicolumn{3}{c}{} \\
Alanine & $373 \pm 48$ & $519 \pm 86$ & $453 \pm 70$ \\
Butanoic acid & $88 \pm 23$ & $129 \pm 26$ & $58 \pm 19$ \\
Dextrose & $2,572 \pm 316$ & $4,420 \pm 238$ & $3,737 \pm 587$ \\
Leucine & $136 \pm 33$ & $251 \pm 40$ & $166 \pm 27$ \\
\hline
\end{tabular}

Metabolites were detected by GC $\times$ GC-TOFMS, PARAFAC signal ratios selected the top 15 candidates, and then repeatedmeasures ANOVA and the post hoc Dunnett test were performed. Section A lists metabolites that peaked immediately but declined (acute HIE response), section B lists those that increased gradually after birth (developmental response) and section $\mathrm{C}$ lists those that were not statistically different from baseline. ${ }^{*} p \leq 0.05,{ }^{* *} p \leq$ $0.01,{ }^{* * *} p \leq 0.001$; Dunnett test versus $0 \mathrm{~h}$.

noid hemorrhage was also present in this case. In contrast, animal 1 showed less severe pathology, with diffuse gliosis but no obvious apparent neuronal loss. A summary of the brain histopathological findings is presented in Table 3.

Dual-immunofluorescence labeling was conducted to assess the GFAP and Nogo-A expression because expression of the latter has been observed in other models of brain injury. Nogo-A, while mainly expressed in oligodendrocytes, is also found in other neural cell types, such as astrocytes [14], so colabeling with GFAP, a marker of reactive astrocytes, was performed to exclude Nogo-Aexpressing astrocytes. In the thalamus and corpus striatum of the control fetal brains, minimal GFAP immunoreactivity was present (Fig. 7D) and Nogo-A was detected in the cytoplasm of many oligodendroglial cells (Fig. 7F). In contrast, gliotic foci in the thalamus and corpus striatum were highly enriched in the GFAP-positive astro- cytes (Fig. 7C), but showed no consistent increase in the density or fluorescent intensity of Nogo-A+ cells (Fig. 7E). As expected, Nogo-A and GFAP did not colocalize, consistent with the expression in the oligodendroglia and astrocytes, respectively (Fig. 7G).

\section{Transmission Electron Microscopy}

TEM images taken of the corpus callosum were evaluated and compared to H\&E images from the same region. Ultrastructural white-matter abnormalities, including perinuclear vacuolation and/or axonal dilation, were apparent in 3 of 4 animals. Figure 8 presents light microscopy and TEM images comparing animal 1 , which had mild white matter injury, to animal 3 , which had more severe white matter injury. Animal 2 had similar TEM findings to animal 3 , and animal 4 appeared to have the most severe white matter injury, although artifacts on TEM confounded critical assessment of this animal.

\section{Plasma Metabolomics}

Hundreds of metabolites were detected by GC $\times$ GCTOFMS in plasma collected from the 4 animals. PARAFAC signal ratios were sorted to select the top 15 metabolites for post hoc analysis. Table 4 lists the average signal intensity values for the top 15 metabolites at baseline $(0 \mathrm{~h})$, immediately after resuscitation $(0.1 \mathrm{~h})$, and on day 1 of age $(24 \mathrm{~h})$. Table 4 is sorted to distinguish the metabolites that peaked immediately after UCO (section A), gradually increased after birth (section B), or were not significantly affected (section C). Based on TEM and histology images, ordinal scores of severity of white matter injury were assigned, so that Spearman $r$ correlations between the metabolite concentrations and severity of injury could be performed at each time point. In the baseline cord blood, choline and myoinositol both correlated negatively with injury (both $r-0.948, p<0.001$ ), at $5 \mathrm{~min}$ dextrose correlated negatively with injury $(r-0.948, p<$ 0.001 ), and at $24 \mathrm{~h}$ erythropentonic acid correlated negatively with injury $(r-0.950, p<0.001)$.

Fig. 7. $H \& E(\mathbf{A}, \mathbf{B})$ and dual immunofluorescence (C-H) images from the putamen of animal $4(\mathbf{A}, \mathbf{C}, \mathbf{E}, \mathbf{G})$ versus a control fetus (B, D, G, H). C Marked hypercellularity is present in the putamen of the experimental animal, due in part to the accumulation of GFAPpositive astrocytes). E, F Nogo-A (NOGO) immunofluorescence highlights the perikarya of oligodendroglial cells, which are GFAPnegative and showed no consistent difference in the density or intensity of immunoreactivity between experimental and control animals. Scale bars, $100 \mu \mathrm{m}$.

(For figure see next page.)
116

Dev Neurosci 2017;39:107-123

DOI: $10.1159 / 000456658$
McAdams/McPherson/Kapur/Juul 

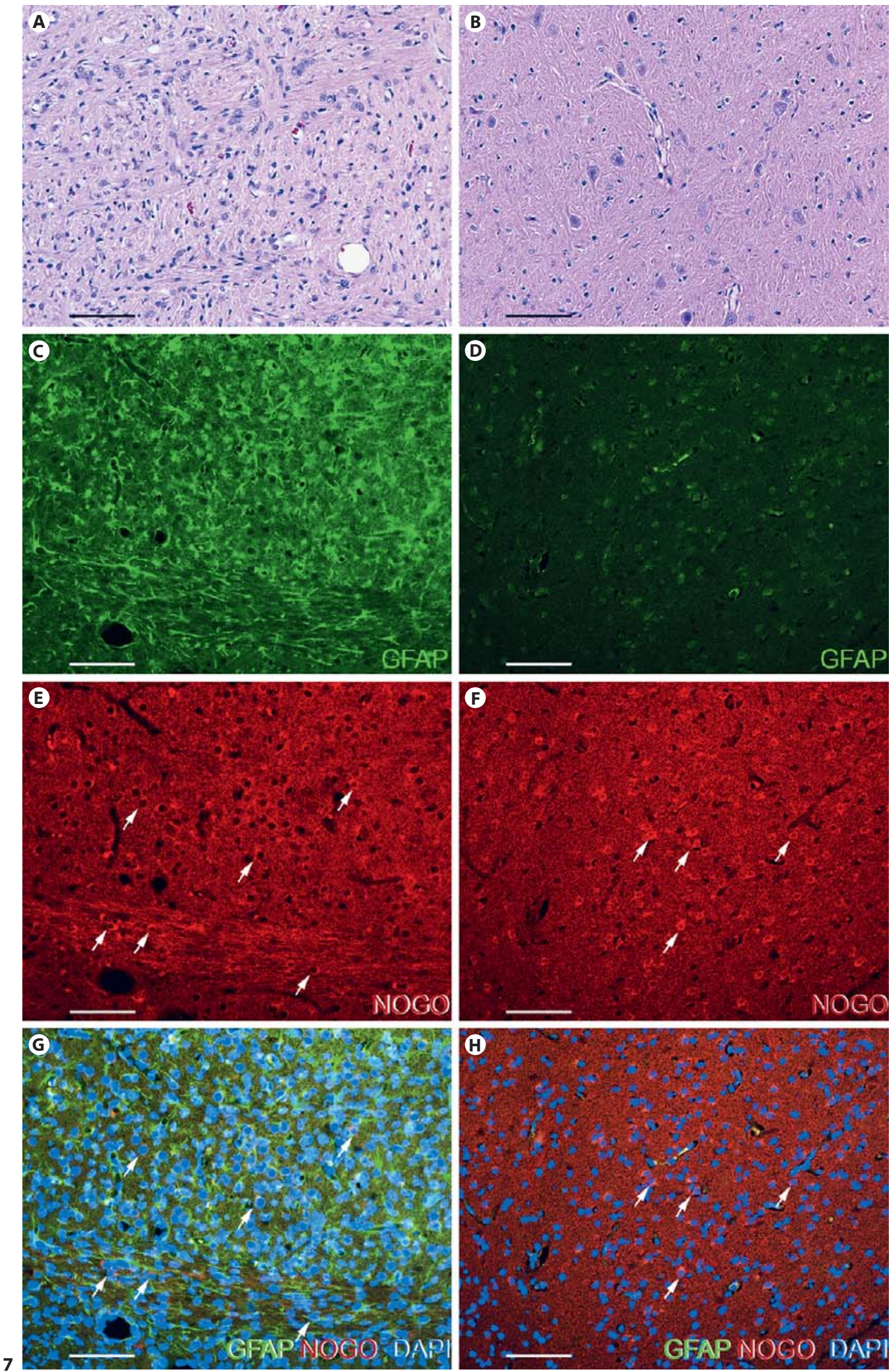

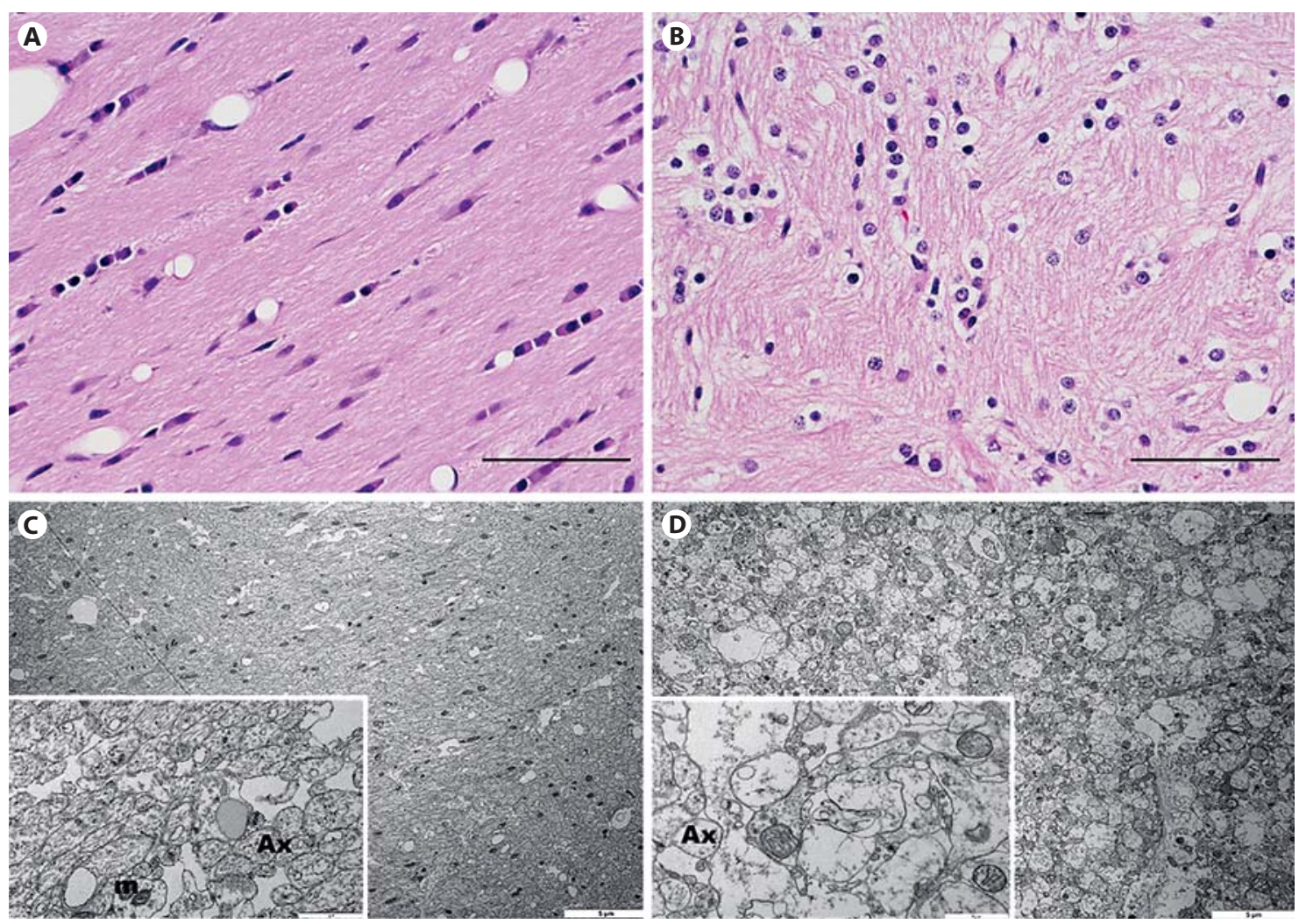

Fig. 8. Light microscopic and ultrastructural images of white matter (cerebral white matter and corpus callosum) from asphyxiated nonhuman primates. A Animal 1. B Animal 3. H\&E. Scale bar, 50 $\mu \mathrm{m}$. B The architecture is more disorganized (although this appearance may be enhanced by the somewhat cross-sectional orientation in this image), with separation of axonal fibers and in- creased glial cell profiles. C, D Transmission electron microscopic images. Scale bar, $5 \mu \mathrm{m} . \times 30,000$ with insets $(\times 30,000$; scale bar, $1 \mu \mathrm{m})$. Insets Highlight axons (Ax) to illustrate dilated axons in animal 3 (D) compared to in animal 1 (C). Mitochondria (m) are indicated. Animal 2 had similar TEM findings to animal 3 (images not shown).

\section{Discussion}

The primate UCO model of HIE was developed to provide translational information about the metabolic, neurologic, and behavioral consequences of birth asphyxia $[7,8,10]$. Consistent with these reports, UCO produced moderate-to-severe HIE manifested by abnormal physical findings and blood gas parameters that satisfied established entry criteria used to qualify human infants in trials studying TH $[5,6]$. However, despite incremental increases of the UCO duration from 12 to $18 \mathrm{~min}$, this model lacked evidence of MRI-detectable brain injury consistent with patterns seen in human neonates with HIE. Efforts to achieve MRI-detectable brain injury by extending the UCO beyond 18 min resulted in excessive mortality. Therefore, our model was modified to include postnatal mechanical ventilation and hypoxia exposure, in order to better simulate the clinical scenario seen in neonates with moderate-to-severe HIE. Animals were also delivered slightly earlier, since brain maturation in nonhuman primate is accelerated compared to in human development. We report on a cohort of animals that underwent UCO for $18 \mathrm{~min}$, similar to animals described in previous experiments [8]. We also exposed $4 \mathrm{UCO}$ animals to postnatal mechanical ventilation, intermittent hypoxia to simulate apnea, and prolonged sedation. These added postnatal factors, which were not part of our previous model, likely contributed to the brain injury involving the ventral posterolateral thalamus, as demonstrated on MRI at 8 days of age in 3 of the 4 animals.

In the 1970s, Myers [15] demonstrated that acute, profound asphyxia produced predominantly deep gray-matter lesions involving the basal ganglia and thalamus, compared to prolonged partial asphyxia, which produced cerebral white matter injury. Most newborns with basal ganglia and thalamic injury on MRI have a history of 
acute and profound asphyxia, consistent with a clinical history of uterine or umbilical cord rupture, placental abruption, traumatic delivery, umbilical cord kinking, APGAR score $<5$ after $5 \mathrm{~min}$, and umbilical cord $\mathrm{pH}<7$ [16]. Miller et al. [17] described 2 pathological patterns of brain injury detected by MRI (performed at a median of 6 days of age; range, 1-24 days) in 173 term newborns with HIE: watershed-predominant and basal ganglia/ thalamus-predominant. Compared to normal and watershed-predominant patterns, the basal ganglia/thalamuspredominant pattern was associated with increased emergency cesarean section delivery, intensive resuscitation after delivery, the most severe clinical encephalopathy and seizures, the lowest Mental Development Index of the Bayley Scales of Infant Development II, and the most severe neuromotor impairments at follow-up at 30 months of age. Similar to the human neonates with basal ganglia/ thalamus injury described by Miller et al. [17], the 4 animals described in our cohort analysis required intensive resuscitation after delivery, had evidence of clinical encephalopathy, and demonstrated seizure activity (3 of 4 animals).

This pilot study is the first to detect thalamic lesions on MRI in our nonhuman primate model of perinatal asphyxia. Postnatal hypoxia episodes, prolonged sedation, or the stress of prolonged ventilation (all factors that are common in critically ill human infants) may have contributed to the vulnerability of the ventral posterolateral thalamus in the setting of HIE. MRI data from 500 term HIE infants demonstrated that $75 \%$ of the patients had some degree of thalamic injury [18]. In fact, when abnormal motor outcomes were correlated with patterns of MRI injury, thalamic injury was associated with the most severe motor abnormalities and was predictive of cerebral palsy (CP) [19]. Although hypoxic-ischemic (HI) injury has been the speculative cause of HIE-related thalamic damage, definitive conclusions have been elusive, in part because the timing of the injury is often unknown, and MRIs and histological data have not been obtained within the same time frame [20]. Our study addresses this issue because the mechanism of injury is known (i.e., UCO) and both MRI and brain tissues for histological analysis were collected at 8 days of age. Three of the 4 animals had MRI evidence of bilateral ventral posterolateral thalamic injury. The posterior and lateral ventral thalamic nuclei are the most vulnerable to total asphyxia injury [15]. While sufficient concurrent controls were not available to compare MRS findings, comparisons with animals from a previous study of $\mathrm{UCO}_{18 \mathrm{~min}}$ [8] suggest that the addition of postnatal factors (e.g., hypoxia, mechanical venti-

HIE Model in Nonhuman Primates lation, and prolonged sedation) affected MRS metabolite expression. The 4 animals exposed to $\mathrm{UCO}_{18}$ min plus postnatal hypoxia had a lower mean NAA/Cr ratio than the historical controls (Table 2). The decreased NAA/Cr ratio, a metabolic marker reflecting the functional status of neurons and axons in the brain, implies neuronal or axonal loss or dysfunction [21]. The decreased NAA/Cr ratio in the $\mathrm{UCO}_{18}$ min plus postnatal hypoxia animals compared to historical animals subjected to $\mathrm{UCO}_{18 \text { min }}$ alone may suggest worse brain injury in the model we used; however, MRS data in our animals and the historical controls were obtained at different time points, so caution is warranted when interpreting these comparative data. Given the MRI, MRS, and brain pathology findings, our experimental paradigm may be a suitable model for detecting the deep nuclear/brain stem injury pattern seen in human neonates with HIE associated with severe, abrupt $\mathrm{HI}$ insults.

Acquired brain injuries resulting from in utero HI events can be associated with damage to neuronal populations (e.g., in the basal ganglia and cortex) and cerebral white matter, e.g. cellular necrosis and axonal damage, which may lead to CP. For over a decade, there has been a call for better animal models to study the pathogenesis of white matter injury associated with $\mathrm{CP}$ in term infants [22], with the recognition that a more thorough knowledge of oligodendrocyte development and physiology is essential for understanding the pathobiology of HIE [23]. We previously reported that UCO for 15-18 min resulted in death or moderate-to-severe CP in $43 \%$ of saline-treated and $44 \%$ of TH-treated animals followed to 9 months of age in a term nonhuman primate model of perinatal asphyxia that included 56 M. nemestrina [8]. We speculated that our current $\mathrm{UCO}_{18 \text { min }}$ model, which included postnatal hypoxic episodes, would also produce animals with CP if long-term follow-up were feasible. Therefore, we investigated whether Nogo-A expression, which is associated with disrupted myelin formation in oligodendrocytes, would be present in our model of severe HIE. Nogo-A, a member of the reticulon family mainly expressed in oligodendrocytes [24], is a master regulator of central nervous system (CNS) plasticity that can restrict structural remodeling and hinder axon regeneration during injury $[13,14,25]$. In adult animal models, the inhibition of Nogo-A improves plastic adaptations and promotes functional recovery after CNS injury [26]. While animals exposed to $\mathrm{UCO}_{18} \mathrm{~min}$ and postnatal hypoxia demonstrated anti-Nogo-A staining of oligodendrocytes in the thalamic and striatal regions, anti-Nogo-A staining was also demonstrated in the 2 control animals. Due to

Dev Neurosci 2017;39:107-123 DOI: 10.1159/000456658 
limited animal numbers, our study cannot rule out a role for Nogo-A limiting functional recovery and neural repair following HI-induced brain injury. Further studies in preterm and term animal models are needed to determine if Nogo-A is involved in the pathogenesis of HIE and the development of CP.

Critical care of newborns with moderate-to-severe HIE often requires sustained mechanical ventilation, which is frequently associated with prolonged sedation of patients [27]. In our model, prolonged sedation of mechanically ventilated HIE animals was feasible using either morphine or DEX, an $\alpha_{2}$-adrenergic receptor agonist that is often used in neonatal intensive care units for sedation and pain management $[28,29]$. While sedation with DEX may be beneficial for neonates with HIE based on animal models [30-32], pharmokinetics data in the setting of HIE are lacking. The sedation scores and pharmokinetics data we collected suggest that morphine and DEX provide suitable sedation in HIE animals; however, our small study numbers prevent any definitive conclusions regarding the safety and efficacy of these sedatives in the setting of HIE.

Animal models permit the direct study of the pathophysiological mechanisms underlying disease states. Neonatal rodent models are advantageous because pups exhibit postnatal brain growth analogous to 3rd-trimester human development, and litters are readily produced and simple to manage. Techniques used to create perinatal hypoxic brain injury in rodents involve unilateral ligation of the common carotid artery combined with hypoxia [33], prolonged hypoxia [34], or temporary occlusion of the middle cerebral artery [35]. The principal disadvantages of neonatal rodent models are related to their lissencephalic brain organization, a lower white matter/gray matter ratio compared to primates, and their more limited behavioral repertoire. Unlike rodents, nonhuman primate brain development and complexity are similar to those in humans, allowing for complex neurocognitive testing over time [36-39].

Despite many attractive attributes akin to human neonates, numerous problems are inherent in working with nonhuman pregnant primates as models of human neonatal HIE. Beyond the expense of the model, the existing ambiguities surrounding human neonatal HIE, such as the plethora of unanswered questions regarding the underlying etiologies that lead to the moderate-to-severe HIE phenotype, make accurate animal model development a challenge. The nonhuman pregnant primate model requires exposure to general anesthesia for isolation and clamping of the fetal umbilical cord, analogous to an ex utero intrapartum treatment procedure (EXIT procedure), in which the baby is partially delivered through the opening of a midline classical cesarean section of the anesthetized mother's abdomen and uterus, but remains attached by its umbilical cord to the placenta. During this EXIT procedure, an umbilical artery catheter is placed, which can be difficult, but is necessary in order to obtain blood gases after delivery. In human neonates who develop HIE, poor fetal reactivity often leads to an emergency cesarean, and therefore the sequence of anesthesia may be reversed to that of our model (i.e., anesthesia, then hypoxia-ischemia in nonhuman primates versus hypoxia-ischemia, then anesthesia in humans). The role of infection or abruption in human HIE is not addressed by our model, and while placental abnormalities may play a significant role in human HIE development, the placenta in the nonhuman primate UCO model is unlikely a factor in the pathologic process, since the clamped umbilical cord is the intended cause of injury. Although the UCO model is imperfect, because of the many analogous features to human neonates with HIE, we are confident that preclinical testing of neuroprotective strategies that may translate to human infants are be best accomplished using a nonhuman primate model $[8,40]$.

Previously, we examined changes in plasma metabolite concentrations in nonhuman primates associated with normal birth compared to animals exposed to perinatal asphyxia $[9,10]$. Several of the metabolites detected in this previous analysis were also identified in this study, including myoinositol and glutamate, and also arachidonic, fumaric, succinic, propanoic and erythropentonic acids. These plasma metabolites, which can be detected using GC $\times$ GC-TOFMS, even with a limited number of available samples, appear to be biomarkers of perinatal asphyxia. Many of them are associated with general biochemical pathways and/or the tricarboxylic acid (TCA) cycle pathway. For example, myoinositol is the precursor to inositol trisphosphate [41], a key mediator of signaling and regulatory functions such as gene expression [42], fat metabolism [43], and calcium homeostasis [44]. The amino acid glutamate is a signaling molecule and a key factor in cellular reduction-oxidation (redox) reactions [45]. Fumaric and succinic acids, TCA cycle intermediates necessary for aerobic redox metabolism, demonstrated a transient postnatal increase following UCO. At birth, the abrupt transition from a relatively hypoxic intrauterine to a normoxic extrauterine environment, oxygen may produce oxidative stress [46], so fetal mechanisms may be in place to upregulate signaling factors that mediate redox reactions [47]. The effects of perinatal asphyxia, an event 
associated with an extreme hypoxic to hyperoxic birth transition, on these oxidative stress pathway signaling factors need further study, but may involve TCA cycle intermediates. In the animals in this study and the earlier one, we observed that several TCA cycle intermediates were acutely elevated while other molecules (e.g., myoinositol, glutamate, etc.) were gradually elevated. This expression pattern suggests that birth transition involves separate metabolic processes which are detectable in the plasma metabolome [9].

The UCO model of HIE is a sophisticated effort to develop a translational platform for identifying biomarkers that correlate with asphyxia-induced injury and testing neurotherapeutic strategies to mitigate HIE. This pilot study, which describes a cohort of animals with UCOinduced HIE that underwent prolonged ventilation, sedation, and repeated hypoxia exposure, has many limitations. It was limited by size, lacked proper control animals, and did not include brain stereology or long-term outcomes. The small sample size hindered statistical analysis and prevented definitive conclusions regarding the observed changes in plasma biomarkers, structural, sexdependent, long-term abnormalities after neonatal ischemia [48], and the comparative effects of sedatives in the setting of HIE secondary to $\mathrm{UCO}_{18 \mathrm{~min}}$. In addition, our pathohistological investigation did not include staining for all cell types and regions relevant to HIE. In a recent study by Pagida et al. [49], involving 15 human neonates (14 delivered at or near term, and 1 preterm) mainly delivered by emergency cesarean section (11/15), the subjects with neuropathological lesions consistent with abrupt/severe perinatal HI injury demonstrated intense immunohistochemical tyrosine hydroxylase expression in the majority of locus coeruleus neurons, a finding which the authors suggest may lead to monoaminergic neurotransmission dysregulation and predispose survivors to long-term psychiatric disorders with or without neurological problems. Future UCO studies on nonhuman primates may benefit from a broader repertoire of immunohistochemical staining (e.g., tyrosine hydroxylase expression, or neural stem and progenitor cells) [49, 50], in order to better correlate the abnormalities present in human neonates with HIE. Despite the small sample size, this pilot study was a necessary step for model refinement and it provided useful information relevant to human newborns with HIE. The plasma metabolite profile corroborates previous findings from animals that have undergone perinatal asphyxia, and suggests that specific TCA cycle intermediates are altered in response to perinatal asphyxia exposure. This non-hypothesis-driven

HIE Model in Nonhuman Primates analysis of plasma metabolites can foster future hypothesis-driven studies that will improve our capacity to diagnose and treat neonatal conditions.

Myers [15] described a model of basal ganglia/thalamus injury. Our $\mathrm{UCO}_{18 \text { min }}$ plus postnatal hypoxia model adds to this previous model since it provides contemporary approaches to assess brain injury and detect potential biomarkers, including MRI, MRS, and metabolomic data. This modification of our previous model, which adds several stressors to the 18 min of hypoxia-ischemia, raises the question of whether postnatal factors may contribute to the poor outcomes of infants who present with moderateto-severe encephalopathy. While extremely time-intensive, this $\mathrm{UCO}_{18 \text { min }}$ plus postnatal hypoxia/stress nonhuman primate model may be useful for understanding the injury mechanisms, potential biomarkers, and therapeutic strategies in neonates with HIE.

\section{Acknowledgments}

We would like to give thanks to Hannah Kinney and Robin Haynes for their helpful direction and expertise, Jessica Snyder for reviewing the TEM images, and also Brittany Baker, Sarah Ramelli, Marianne Bricker, Kelly Ledbetter, Brian Phillips, Nina Natarajan, and Todd Richards for expert assistance. Special thanks to Washington National Primate Research Center personnel, Cliff Astley, Audrey Baldessari, Bruce Brown, Noelle McKain, Clayton Ferrier, and Tom Burbacher, and also to Kristina Adams-Waldorf for providing brain tissues.

\section{Disclosure Statement}

The contents of this paper are solely the responsibility of the authors and do not necessarily represent the official view of NCRR, $\mathrm{NIH}$, or the Institute of Translational Health Sciences or the UW Primate Center. The authors have no financial associations, ties to products or conflicts of interest to disclose.

\section{Funding Sources}

This project was supported in part by NIH grants UL1 RR025014 and the ARRA supplement 3UL1 RR025015-0353 and P51 RR000166 from the National Center for Research Resource (NCRR).
Dev Neurosci 2017;39:107-123

DOI: $10.1159 / 000456658$ 


\section{References}

1 Liu L, Johnson HL, Cousens S, Perin J, Scott S, Lawn JE, Rudan I, Campbell H, Cibulskis R, Li M, Mathers C, Black RE; Child Health Epidemiology Reference Group of WHO, UNICEF: Global, regional, and national causes of child mortality: an updated systematic analysis for 2010 with time trends since 2000. Lancet 2012;379:2151-2161.

2 American College of Obstetricians and Gynecologists: Executive summary: neonatal encephalopathy and neurologic outcome. Obstet Gynecol 2014;123:896-901.

3 Takenouchi T, Kasdorf E, Engel M, Grunebaum A, Perlman JM: Changing pattern of perinatal brain injury in term infants in recent years. Pediatr Neurol 2012;46:106-110.

4 Juul SE, Aylward E, Richards T, McPherson RJ, Kuratani J, Burbacher TM: Prenatal cord clamping in newborn Macaca nemestrina: a model of perinatal asphyxia. Dev Neurosci 2007;29:311-320.

5 Shankaran S, Laptook AR, Ehrenkranz RA, Tyson JE, McDonald SA, Donovan EF, Fanaroff AA, Poole WK, Wright LL, Higgins RD, Finer NN, Carlo WA, Duara S, Oh W, Cotten CM, Stevenson DK, Stoll BJ, Lemons JA, Guillet $\mathrm{R}$, Jobe $\mathrm{AH}$; National Institute of Child Health; Human Development Neonatal Research Network: Whole-body hypothermia for neonates with hypoxic-ischemic encephalopathy. N Engl J Med 2005;353:1574-1584.

6 Gluckman PD, Wyatt JS, Azzopardi D, Ballard R, Edwards AD, Ferriero DM, Polin RA, Robertson CM, Thoresen M, Whitelaw A, Gunn AJ: Selective head cooling with mild systemic hypothermia after neonatal encephalopathy: multicentre randomised trial. Lancet 2005;365:663-670.

7 Jacobson Misbe EN, Richards TL, McPherson RJ, Burbacher TM, Juul SE: Perinatal asphyxia in a nonhuman primate model. Dev Neurosci 2011;33:210-221.

8 Traudt CM, McPherson RJ, Bauer LA, Richards TL, Burbacher TM, McAdams RM, Juul SE: Concurrent erythropoietin and hypothermia treatment improve outcomes in a term nonhuman primate model of perinatal as phyxia. Dev Neurosci 2013;35:491-503.

9 Beckstrom AC, Humston EM, Snyder LR, Synovec RE, Juul SE: Application of comprehensive two-dimensional gas chromatography with time-of-flight mass spectrometry method to identify potential biomarkers of perinatal asphyxia in a non-human primate model. J Chromatogr A 2011;1218:18991906.

10 Beckstrom AC, Tanya P, Humston EM, Snyder LR, Synovec RE, Juul SE: The perinatal transition of the circulating metabolome in a nonhuman primate. Pediatr Res 2012;71: $338-344$.
11 Volpe J: Neurology of the Newborn, ed 5. Philadelphia, W.B. Saunders, 2008.

12 Provencher SW: Estimation of metabolite concentrations from localized in vivo proton NMR spectra. Magn Reson Med 1993;30: 672-679.

13 Schwab ME, Strittmatter SM: Nogo limits neural plasticity and recovery from injury. Curr Opin Neurobiol 2014;27:53-60.

14 Rolando C, Parolisi R, Boda E, Schwab ME, Rossi F, Buffo A: Distinct roles of Nogo-A and Nogo receptor 1 in the homeostatic regulation of adult neural stem cell function and neuroblast migration. J Neurosci 2012;32: 17788-17799.

15 Myers RE: Two patterns of perinatal brain damage and their conditions of occurrence. Am J Obstet Gynecol 1972;112:246-276.

16 Sie LT, van der Knaap MS, Oosting J, de Vries LS, Lafeber HN, Valk J: MR patterns of hypoxic-ischemic brain damage after prenatal, perinatal or postnatal asphyxia. Neuropediatrics 2000;31:128-136.

17 Miller SP, Ramaswamy V, Michelson D, Barkovich AJ, Holshouser B, Wycliffe N, Glidden DV, Deming D, Partridge JC, Wu YW, Ashwal S, Ferriero DM: Patterns of brain injury in term neonatal encephalopathy. J Pediatr 2005;146:453-460.

18 Okereafor A, Allsop J, Counsell SJ, Fitzpatrick J, Azzopardi D, Rutherford MA, Cowan FM: Patterns of brain injury in neonates exposed to perinatal sentinel events. Pediatrics 2008; 121:906-914.

19 Ferrari F, Todeschini A, Guidotti I, MartinezBiarge M, Roversi MF, Berardi A, Ranzi A, Cowan FM, Rutherford MA: General movements in full-term infants with perinatal asphyxia are related to basal ganglia and thalamic lesions. J Pediatr 2011;158:904-911.

20 Haynes RL, Billiards SS, Borenstein NS, Volpe JJ, Kinney HC: Diffuse axonal injury in periventricular leukomalacia as determined by apoptotic marker fractin. Pediatr Res 2008;63. 656-661.

21 Watanabe H, Fukatsu H, Katsuno M, Sugiura M, Hamada K, Okada Y, Hirayama M, Ishigaki T, Sobue G: Multiple regional ${ }^{1} \mathrm{H}-\mathrm{MR}$ spectroscopy in multiple system atrophy: $\mathrm{NAA} / \mathrm{Cr}$ reduction in pontine base as a valuable diagnostic marker. J Neurol Neurosurg Psychiatry 2004;75:103-109.

22 Johnston MV, Ferriero DM, Vannucci SJ, Hagberg H: Models of cerebral palsy: which ones are best? J Child Neurol 2005;20:984987.

23 Silbereis JC, Huang EJ, Back SA, Rowitch DH: Towards improved animal models of neonatal white matter injury associated with cerebral palsy. Dis Model Mech 2010;3:678-688.

24 Schwab ME: Functions of Nogo proteins and their receptors in the nervous system. Nat Rev Neurosci 2010;11:799-811.
25 Kempf A, Schwab ME: Nogo-A represses anatomical and synaptic plasticity in the central nervous system. Physiology 2013;28:151-163.

26 Zorner B, Schwab ME: Anti-Nogo on the go: from animal models to a clinical trial. Ann NY Acad Sci 2010;1198(suppl 1):E22-E34.

27 Roka A, Melinda KT, Vasarhelyi B, Machay T, Azzopardi D, Szabo M: Elevated morphine concentrations in neonates treated with morphine and prolonged hypothermia for hypoxic ischemic encephalopathy. Pediatrics 2008; 121:e844-e849.

28 Chrysostomou C, Schmitt CG: Dexmedetomidine: sedation, analgesia and beyond. Expert Opin Drug Metab Toxicol 2008;4:619627.

29 McAdams RM, McPherson RJ, Kapur R, Phillips B, Shen DD, Juul SE: Dexmedetomidine reduces cranial temperature in hypothermic neonatal rats. Pediatr Res 2015;77:772-778.

30 Laudenbach V, Mantz J, Lagercrantz H, Desmonts JM, Evrard P, Gressens P: Effects of alpha(2)-adrenoceptor agonists on perinatal excitotoxic brain injury: comparison of clonidine and dexmedetomidine. Anesthesiology 2002;96:134-141.

31 Paris A, Mantz J, Tonner PH, Hein L, Brede M, Gressens P: The effects of dexmedetomidine on perinatal excitotoxic brain injury are mediated by the $\alpha_{2 \mathrm{~A}}$-adrenoceptor subtype. Anesth Analg 2006;102:456-461.

32 Sato K, Kimura T, Nishikawa T, Tobe Y, Masaki Y: Neuroprotective effects of a combination of dexmedetomidine and hypothermia after incomplete cerebral ischemia in rats. Acta Anaesthesiol Scand 2010;54:377-382.

33 Rice JE 3rd, Vannucci RC, Brierley JB: The influence of immaturity on hypoxic-ischemic brain damage in the rat. Ann Neurol 1981;9: 131-141.

34 Stewart WB, Ment LR, Schwartz M: Chronic postnatal hypoxia increases the numbers of cortical neurons. Brain Res 1997;760:17-21.

35 Ashwal S, Cole DJ, Osborne S, Osborne TN, Pearce WJ: A new model of neonatal stroke: reversible middle cerebral artery occlusion in the rat pup. Pediatr Neurol 1995;12:191-196.

36 Burbacher TM, Grant KS: Methods for studying nonhuman primates in neurobehavioral toxicology and teratology. Neurotoxicol Teratol 2000;22:475-486.

37 Kochunov P, Castro C, Davis D, Dudley D, Brewer J, Zhang Y, Kroenke CD, Purdy D, Fox PT, Simerly C, Schatten G: Mapping primary gyrogenesis during fetal development in primate brains: high-resolution in utero structural MRI of fetal brain development in pregnant baboons. Front Neurosci 2010;4:20.

38 Rilling JK: Comparative primate neuroimaging: insights into human brain evolution. Trends Cogn Sci 2014;18:46-55. 
39 Burbacher TM, Grant KS, Worlein J, Ha J, Curnow E, Juul S, Sackett GP: Four decades of leading-edge research in the reproductive and developmental sciences: the Infant Primate Research Laboratory at the University of Washington National Primate Research Center. Am J Primatol 2013;75:1063-1083.

40 Sackett GP, Ruppenthal GC, Davis AE: Survival, growth, health, and reproduction following nursery rearing compared with mother rearing in pigtailed monkeys (Macaca nemestrina). Am J Primatol 2002;56:165-183.

41 Downes CP, Macphee CH: Myo-inositol metabolites as cellular signals. Eur J Biochem 1990;193:1-18.

42 Steger DJ, Haswell ES, Miller AL, Wente SR, O'Shea EK: Regulation of chromatin remodeling by inositol polyphosphates. Science 2003;299:114-116.
43 Rapiejko PJ, Northup JK, Evans T, Brown JE, Malbon CC: G-proteins of fat-cells. Role in hormonal regulation of intracellular inositol 1,4,5-trisphosphate. Biochem J 1986;240:3540.

44 Streb H, Irvine RF, Berridge MJ, Schulz I: Release of $\mathrm{Ca}^{2+}$ from a nonmitochondrial intracellular store in pancreatic acinar cells by inositol-1,4,5-trisphosphate. Nature 1983;306: 67-69.

45 McEntee WJ, Crook TH: Glutamate: its role in learning, memory, and the aging brain. Psychopharmacology 1993;111:391-401.

46 Saugstad OD: Update on oxygen radical disease in neonatology. Curr Opin Obstet Gynecol 2001;13:147-153.

47 Maron JL, Johnson KL, Parkin C, Iyer L, Davis JM, Bianchi DW: Cord blood genomic analysis highlights the role of redox balance. Free Radic Biol Med 2010;49:992-996.
48 Breu M, Zhang J, Porambo M, Pletnikov MV, Goeral K, Kakara M, Johnston MV, Fatemi A: Diffusion tensor imaging abnormalities in the cerebral white matter correlate with sex-dependent neurobehavioral deficits in adult mice with neonatal ischemia. Dev Neurosci 2016;38:83-95.

49 Pagida MA, Konstantinidou AE, Korelidou A, Katsika D, Tsekoura E, Patsouris E, Panayotacopoulou MT: The effect of perinatal hypoxic/ischemic injury on tyrosine hydroxylase expression in the locus coeruleus of the human neonate. Dev Neurosci 2016;38:4153.

50 Kwak M, Lim S, Kang E, Furmanski O, Song $\mathrm{H}$, Ryu YK, Mintz CD: Effects of neonatal hypoxic-ischemic injury and hypothermic neuroprotection on neural progenitor cells in the mouse hippocampus. Dev Neurosci 2015;37: 428-439. 